\title{
VEGF-dependent tumor angiogenesis requires inverse and reciprocal regulation of VEGFR1 and VEGFR2
}

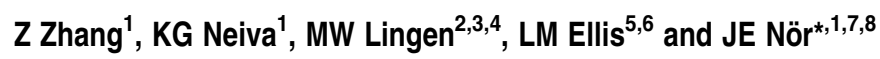

Vascular endothelial growth factor (VEGF) signaling is critical for tumor angiogenesis. However, therapies based on inhibition of VEGF receptors (VEGFRs) have shown modest results for patients with cancer. Surprisingly little is known about mechanisms underlying the regulation of VEGFR1 and VEGFR2 expression, the main targets of these drugs. Here, analysis of tissue microarrays revealed an inversely reciprocal pattern of VEGFR regulation in the endothelium of human squamous-cell carcinomas (high VEGFR1, low VEGFR2), as compared with the endothelium of control tissues (low VEGFR1, high VEGFR2). Mechanistic studies demonstrated that VEGF signals through the Akt/ERK pathway to inhibit constitutive ubiquitination and induce rapid VEGFR1 accumulation in endothelial cells. Surprisingly, VEGFR1 is primarily localized in the nucleus of endothelial cells. In contrast, VEGF signals through the JNK/C-Jun pathway to induce endocytosis, nuclear translocation, and downregulation of VEGFR2 via ubiquitination. VEGFR1 signaling is required for endothelial-cell survival, while VEGFR2 regulates capillary tube formation. Notably, the antiangiogenic effect of bevacizumab (anti-VEGF antibody) requires normalization of VEGFR1 and VEGFR2 levels in human squamous-cell carcinomas vascularized with human blood vessels in immunodeficient mice. Collectively, this work demonstrates that VEGF-induced angiogenesis requires inverse regulation of VEGFR1 and VEGFR2 in tumor-associated endothelial cells.

Cell Death and Differentiation (2010) 17, 499-512; doi:10.1038/cdd.2009.152; published online 16 October 2009

\section{Introduction}

Vascular endothelial growth factor (VEGF) is a key regulator of physiologic angiogenesis, and plays a major role in the pathobiology of cancer. ${ }^{1-3}$ Lack of one vegf allele is sufficient to cause death early in embryonic development due to abnormal vessel development, ${ }^{4,5}$ and autocrine VEGF signaling is required to maintain vascular homeostasis in adult healthy tissues. ${ }^{6}$ The recognition of the prominent role for VEGF in cancer led to the development of antiangiogenic therapies targeting this pathway. ${ }^{3,7}$ Indeed, these therapies have become the standard of care for several malignancies, including metastatic colorectal cancer. ${ }^{3,8}$ However, resistance to antiangiogenic therapies has been shown in xenograft tumor models and in clinical trials. ${ }^{9-11}$ The understanding of mechanisms underlying the regulation and function of VEGF receptors (VEGFRs) is imperative to determine how vascular homeostasis is maintained in health and how these receptors contribute to the pathobiology of angiogenesis-dependent diseases, such as cancer. Furthermore, the understanding of the cellular localization and regulation of these receptors in healthy tissues and in tumors is critical for the improvement of the outcomes of therapies targeted to inhibition of VEGF signaling.

The VEGFRs VEGFR1 and VEGFR2 are structurally related members of the receptor tyrosine kinase (RTK) family that mediate critical signaling pathways in endothelial cells. ${ }^{12-14}$ VEGFR1 is a receptor for VEGF-A, VEGF-B, and placental growth factor (PIGF), and is believed to have low kinase activity. ${ }^{15,16}$ In contrast, VEGFR2 is considered a highly active receptor that mediates broad signaling cascades and regulates many endothelial-cell functions, including proliferation, migration, and differentiation. ${ }^{15,17}$ Ligandmediated degradation of RTKs is an important regulatory step of signaling transduction. It is known that epidermal growth factor (EGF) causes downregulation of EGF receptor (EGFR) by ubiquitination. ${ }^{18}$ VEGF-dependent VEGFR2 downregulation appears to involve endocytosis in either bovine aortic endothelial cells or human endothelial cells. ${ }^{19,20}$ Notably, autophosphorylation of the kinase domain of VEGFR2 is necessary for receptor internalization. ${ }^{21}$ While ligand-mediated downregulation of VEGFR2 has been

\footnotetext{
${ }^{1}$ Angiogenesis Research Laboratory, Department of Restorative Sciences, University of Michigan, Ann Arbor, MI 48109-1078, USA; ${ }^{2}$ Department of Pathology, University of Chicago School of Medicine, Chicago, IL 60637, USA; ${ }^{3}$ Department of Medicine, University of Chicago School of Medicine, Chicago, IL 60637, USA; ${ }^{4}$ Department of Radiation and Cellular Oncology, University of Chicago School of Medicine, Chicago, IL 60637, USA; ${ }^{5}$ Department of Surgical Oncology, MD Anderson Cancer Center, University of Texas, Houston, TX 77030, USA; ${ }^{6}$ Department of Cancer Biology, MD Anderson Cancer Center, University of Texas, Houston, TX 77030, USA; ${ }^{7}$ Department of Biomedical Engineering, University of Michigan, Ann Arbor, MI 48109-1078, USA and ${ }^{8}$ Department of Otolaryngology, School of Medicine, University of Michigan, Ann Arbor, Ml 48109-1078, USA

*Corresponding author: Professor JE Nör, Angiogenesis Research Laboratory, University of Michigan, 1011 N. University Room 2309, Ann Arbor, Ml 48109-1078, USA. Tel: + 734936 9300; Fax: + 734936 1597; E-mail: jenor@umich.edu

Keywords: angiogenesis; apoptosis; receptor tyrosine kinase; tumor microenvironment

Abbreviations: VEGF, vascular endothelial growth factor; VEGFR1, vascular endothelial growth factor receptor-1; VEGFR2, vascular endothelial growth factor receptor-2; RTK, receptor tyrosine kinase; EGF, epidermal growth factor; EGFR, epidermal growth factor receptor; PIGF, placental growth factor; IL-6, interleukin-6; PI3K/Akt, phosphoinositol-3-kinase/Akt; ERK, extracellular signal-regulated kinase; JNK, c-Jun N-terminal kinase; STAT3, signal transducer and activator of transcription-3; HDMEC, human dermal microvascular endothelial cell; HPEC, human pulmonary endothelial cell; FBS, fetal bovine serum; CM, conditioned medium Received 16.3.09; revised 25.8.09; accepted 15.9.09; Edited by G Rabinovich; published online 16.10.09
} 
described, mechanisms underlying the reciprocal upregulation of VEGFR1 in endothelial cells exposed to VEGF and the impact of this reversal of expression levels to endothelial cell proliferation, sprouting, survival, and tumor angiogenesis have not been characterized. In this study, we showed that VEGF-induced upregulation of VEGFR1 is dependent on Akt and extracellular signal-regulated kinase (ERK) signaling, while downregulation of VEGFR2 is mediated by the c-Jun $\mathrm{N}$-terminal kinase (JNK)-C-Jun pathway. Gene silencing and functional studies demonstrated that VEGFR1 signaling is critical for endothelial-cell survival, while VEGFR2 signaling is required for capillary tube formation. Notably, the antiangiogenic effect of the monoclonal anti-VEGF antibody bevacizumab in vivo correlates with the reversal of VEGFR1 and VEGFR2 levels in the vascular endothelial cells of squamouscell carcinomas.

\section{Results}

VEGF reverses VEGFR1 and VEGFR2 protein levels in endothelial cells. A tissue microarray containing a panel of human squamous cell-carcinomas ${ }^{22}$ was used to evaluate VEGFR1 and VEGFR2 protein levels in tumor-associated endothelial cells. We found more VEGFR1-positive blood vessels in human squamous-cell carcinomas than in the control tissues, that is, oral mucosa (Figure 1a and b). In contrast, VEGFR2-positive vessels were more prevalent in oral mucosa than in the tumor environment (Figure $1 \mathrm{a}$ and $\mathrm{b}$ ). Notably, while in human tumors the majority of blood vessels are VEGFR1-positive, in the oral mucosa most vessels are VEGFR2-positive (Figure 1b). As expected, human squamous-cell carcinomas strongly express VEGF (Figure 1a). To evaluate the spatial relationship between VEGFR expression and VEGF, we performed immunostaining of serial and sequential tissue sections from xenografted human squamous-cell carcinomas grown in SCID mice. Confirming the data from the tissue microarrays, we observed strong immunostaining for VEGF and VEGFR1, and weaker staining for VEGFR2 in the xenograft tumors (Supplementary Figure 1). To begin to understand the mechanisms involved in the regulation of VEGFR1 and VEGFR2 expression, we exposed primary human dermal microvascular endothelial cells (HDMECs) to increasing concentrations of fetal bovine serum (FBS). Whereas FBS downregulated VEGFR2, it potently induced VEGFR1 in HDMECs (Figure 1c). Knowing that ligands exert regulatory functions on their own receptors, that FBS contains VEGF, and that human squamous-cell carcinomas express high levels of VEGF, we evaluated the effect of recombinant VEGF on the regulation of VEGFR1 and VEGFR2. VEGF induced the expression of VEGFR1 while downregulating VEGFR2 in two primary endothelial-cell types, HDMECs and human pulmonary endothelial cells (HPECs) (Figure 1d). Treatment with anti-VEGF antibody inhibited VEGF-regulatory effects on VEGFR1 and VEGFR2 in a dose-dependent manner, demonstrating specificity of responses (Figure 1e). To further verify the specificity of VEGFR regulation, we evaluated the effect of EGF, which is known to downregulate its tyrosine kinase receptor. ${ }^{18}$ EGF downregulated EGFR in squamous-cell carcinoma cells (Figure $1 \mathrm{~g}$ ), but had no effect on the expression levels of VEGFR1 and VEGFR2 in endothelial cells (Figure 1f and h). Likewise, the VEGF-receptor ligand PIGF, and the angiogenic cytokine interleukin-6 (IL-6), had no effect on VEGFR1 or VEGFR2 expression (Figure $1 f$ and i).

The reversal of VEGFR1 and VEGFR2 protein levels in endothelial cells happened within minutes of exposure to VEGF (Figure 1h), which suggested that this process was not regulated at the transcriptional level. Reverse transcriptase polymerase chain reaction (RT-PCR) and real-time PCR ( $q P C R$ ) analyses confirmed this hypothesis showing that VEGF had no effect on VEGFR1 or VEGFR2 mRNA within the same timeframe (Figure $2 a$ and $b$ ). We then reasoned that intracellular receptor trafficking and differential regulation of ubiquitination might be involved in the process of VEGFinduced regulation of VEGFR1 and VEGFR2. Confocal microscopy showed that VEGFR2 is translocated to the nucleus within $30 \mathrm{~min}$ of VEGF treatment (Figure 2c). Surprisingly, most of the VEGFR1 is found in the nucleus of untreated or VEGF-treated HDMECs (Figure 2c). Cell fractionation studies confirmed that VEGFR1 is mainly expressed in the nucleus, while VEGFR2 is in the cytoplasmic/cell membrane fraction in untreated cells (Figure $2 d$ ). VEGFR1 remained in the nucleus upon treatment with VEGF, while VEGFR2 translocated from the cytoplasmic/cell membrane fraction to the nucleus (Figure 2d). EGF and IL-6 did not affect VEGFR2 localization (Figure 2e). Treatment with concanavalin-A (Con-A) revealed that VEGF-induced VEGFR2 nuclear translocation depends on endocytosis

\footnotetext{
Figure 1 VEGF inversely regulates VEGFR1 and VEGFR2 in endothelial cells. (a) Immunohistochemical analysis of VEGFR1, VEGFR2, and VEGF expression (brown staining) in representative specimens from human squamous-cell carcinomas or normal human oral mucosa. Arrows indicate blood vessels. Scale bars: left panels, $50 \mu \mathrm{m}$ ( $\times 100)$; right panels, $20 \mu \mathrm{m}(\times 400)$. (b) Quantification of VEGFR1- and VEGFR2-positive blood vessels $(\times 100)$ in normal human oral mucosa and human squamous-cell carcinomas (HSCCs) from the human tissue microarrays used in panel a; ${ }^{*}$, number of VEGFR1-positive versus VEGFR2-positive vessels in the oral mucosa $(P<0.001)$; ${ }^{* *}$, number of VEGFR1-positive versus VEGFR2-positive vessels in HSCCs $(P<0.001) ;{ }^{* *}$, VEGFR1-positive vessels in the oral mucosa versus VEGFR1-positive vessels in HSCCs $(P<0.001)$; ${ }^{* \star \star}$, VEGFR2-positive vessels in the oral mucosa versus VEGFR2-positive vessels in HSCCs $(P=0.005)$. (c) Primary HDMECs were serum-starved overnight and then were incubated with increasing concentrations of FBS for $24 \mathrm{~h}$. (d) HDMECs or primary HPECs were serum-starved overnight and then treated with $50 \mathrm{ng} / \mathrm{ml} \mathrm{VEGF}_{165}$ for the indicated time points. (e) HDMECs were starved overnight, pre-incubated with 0-5 $\mu \mathrm{g} / \mathrm{ml}$ anti-VEGF neutralizing antibody for $1 \mathrm{~h}$, and treated with $50 \mathrm{ng} / \mathrm{ml} \mathrm{VEGF}{ }_{165}$ for additional $2 \mathrm{~h}$ in the presence of the anti-VEGF antibody. Isotype-matched lgG was used as negative control. (f, g) HDMECs (f) or UM-SCC-1 cells (g) were serum-starved and treated with $50 \mathrm{ng} / \mathrm{ml} \mathrm{EGF,} 50 \mathrm{ng} / \mathrm{ml} \mathrm{VEGF}{ }_{165}$, or $20 \mathrm{ng} / \mathrm{ml} \mathrm{IL-6} \mathrm{for} 24 \mathrm{~h}$. Alternatively, cells were cultured in $5 \%$ FBS. (h, i) HDMECs were treated with $50 \mathrm{ng} / \mathrm{ml} \mathrm{EGF,} 50 \mathrm{ng} / \mathrm{ml} \mathrm{VEGF}_{165}$ (h), $50 \mathrm{ng} / \mathrm{ml}$ PIGF (i), or left untreated for the indicated time points. VEGFR1, VEGFR2, and EGFR expression was detected by Western blots. (c-i) The molecular weight for the VEGFR1 bands is approximately $200 \mathrm{kDa}$, and for the VEGFR2 bands is approximately $220 \mathrm{kDa}$. Numbers depicted in the Western blots represent the quantification of band density normalized initially by GAPDH, and then normalized by untreated controls
} 
(Figure 2f). However, blockade of nuclear translocation did not prevent VEGF-induced VEGFR2 downregulation (Figure 2f). Interestingly, only the high-molecular-weight
VEGFR2 isoform translocated into the nucleus upon treatment with VEGF (Figure $2 \mathrm{~d}-\mathrm{g}$ ). To determine the glycosylation state of the VEGFR2 isoform translocated to the nucleus,
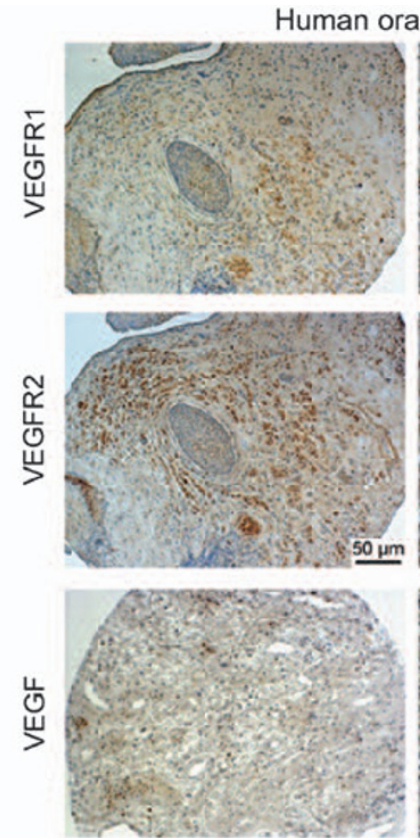

b

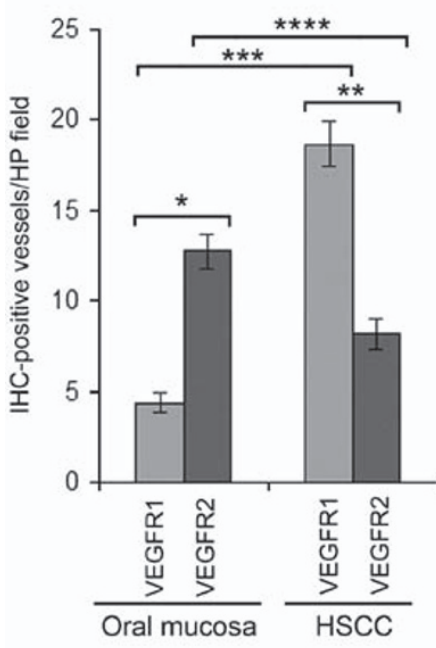

C

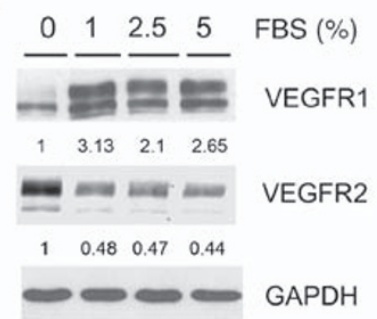

e - - - - $+\lg G$

$= \pm= \pm$ VEGFR-1

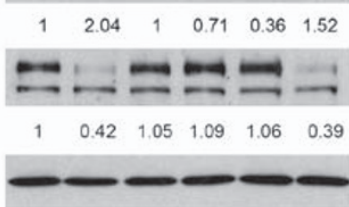

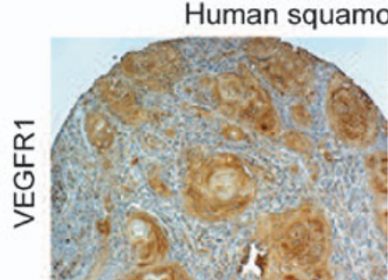
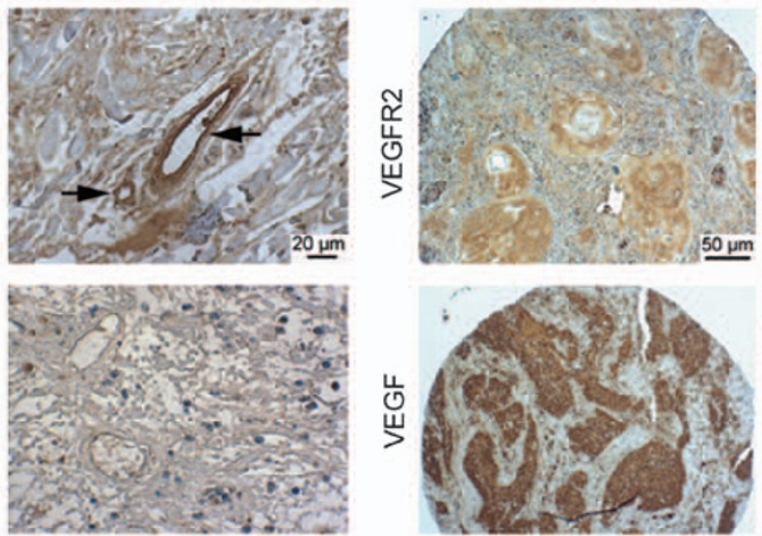
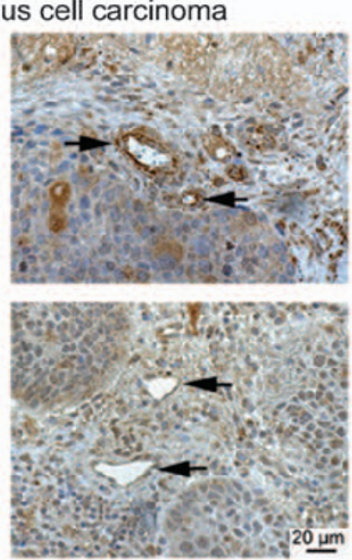

d

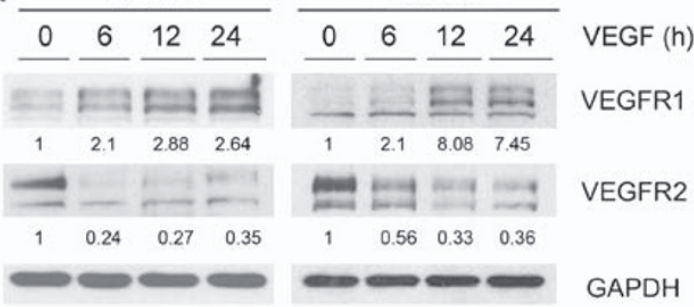

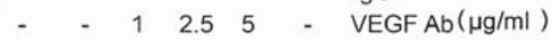

$+ \pm+ \pm+\operatorname{VEGF}(50 \mathrm{ng} / \mathrm{ml})$

VEGFR-2

GAPDH

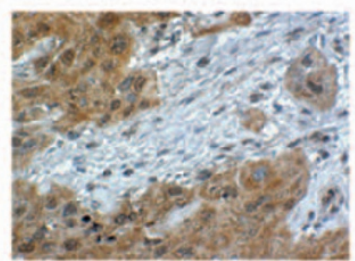

GAPDH

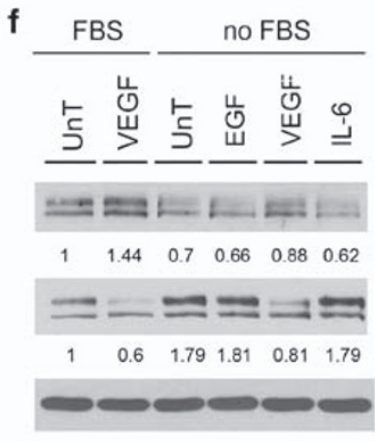

VEGFR1

VEGFR2

GAPDH

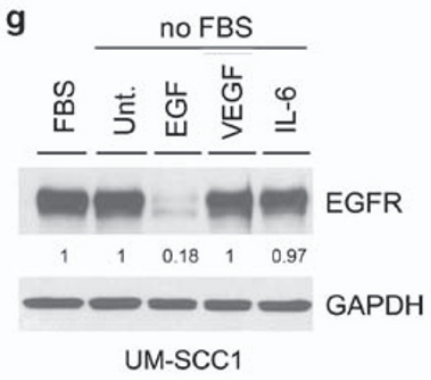

\begin{tabular}{|c|c|c|c|c|}
\hline \multicolumn{4}{|c|}{ PIGF } & \multirow[b]{2}{*}{ Time (min) } \\
\hline 0 & 15 & 30 & 60 & \\
\hline$E$ & 린 & 36 & $\underline{E-3}$ & VEGFR1 \\
\hline 1 & 0.98 & 1.03 & 0.95 & \\
\hline$\Rightarrow$ & $=$ & $\Rightarrow$ & $=$ & VEGFR2 \\
\hline 1 & 1.07 & 1.03 & 1.06 & \\
\hline & 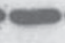 & 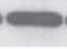 & 10 & GAPDH \\
\hline
\end{tabular}


we treated cell lysates with an enzymatic cocktail that eliminates all $\mathrm{N}$-linked and most $\mathrm{O}$-linked forms. Interestingly, we observed that both VEGFR2 isoforms are glycosylated (Figure 2g), suggesting that the nuclear translocation is not differentially regulated by VEGFR2 glycosylation.

\section{VEGF-induced VEGFR2 downregulation requires} signaling through the JNK-c-Jun pathway and activity of the ubiquitin-proteasome system. To evaluate the role of the ubiquitin-proteasome system on VEGF-induced VEGFR2 downregulation, HDMECs were exposed to VEGF in presence of specific inhibitors. We observed that inhibition of ubiquitin or proteasome activity partially prevented VEGF-induced VEGFR2 downregulation, but not nuclear translocation (Figure $3 a$ and b). It is known that JNK targets ubiquitination of regulatory proteins. ${ }^{23}$ HDMECs exposed to VEGF showed strong phosphorylation of JNK-2, and to some extent JNK-1, resulting in c-Jun activation (Figure $3 \mathrm{c}$ and $\mathrm{d}$ ). Notably, phosphorylation of JNK correlated with marked decrease in VEGFR2 protein levels (Figure $3 c$ and d). Indeed, blockade of JNK activity inhibited VEGF-mediated VEGFR2 downregulation and partially blocked VEGFR1 upregulation in HDMECs and HPECs (Figure $3 e$ and f). However, inhibition of JNK activity did not affect VEGF-induced VEGFR2 nuclear translocation (Figure $3 \mathrm{~g}$ ). We also evaluated two additional means of directly inducing JNK activity, UV radiation and anisomycin. ${ }^{24}$ Both strategies were sufficient to downregulate VEGFR2 protein levels in endothelial cells, bypassing the requirement for VEGF (Supplementary Figure $2 a$ and b). Of note, blockade of JNK and c-Jun phosphorylation with SP600125 prevented anisomycin-induced downregulation of VEGFR2 (Supplementary Figure 2b). Taken together, these data demonstrated that signaling through the JNK/c-Jun pathway and activity of the ubiquitin-proteasome system are necessary for VEGF-induced downregulation of VEGFR2 protein levels in primary endothelial cells.

\section{VEGF signals through PI3k/Akt to inhibit ubiquitination and rapidly increase VEGFR1 levels in endothelial cells. Since VEGFR1 expression was upregulated within minutes of exposure to VEGF, we hypothesized that VEGFR1 was continuously being degraded by the ubiquitin-proteasome system to maintain its homeostatic levels. This hypothesis was confirmed by the observation that inhibition of either ubiquitin or proteasome activity was}

sufficient to rapidly induce VEGFR1 expression (Figure $3 \mathrm{~h}$ and i). Then, we evaluated the function of the phosphoinositol-3-kinase/Akt (PI3K/Akt) and ERK pathways in VEGF-induced VEGFR1 expression in HDMECs (Figure 3j-I). Inhibition of either Akt or ERK1/2 phosphorylation suppressed VEGF-mediated VEGFR1 upregulation, but had no effect on VEGFR2 protein levels (Figure 3k and I).

VEGFR1 signaling is required for the antiapoptotic effect
of VEGF, while VEGFR2 signaling is required for VEGF-
induced capillary tube formation. It is known that VEGF protects endothelial cells against apoptosis induced by growth factor starvation (Figure $4 \mathrm{a}$ ) ${ }^{25}$ To evaluate the relative role of VEGFR1 and VEGFR2 in endothelial-cell survival, we used shRNA-mediated gene silencing with lentiviral vectors (Figure 4b). Unexpectedly, shRNAmediated downregulation of VEGFR2 resulted in upregulation of VEGFR1 protein levels, while downregulation of VEGFR1 did not affect VEGFR2 protein (Figure 4b). VEGFR1 knockdown had a stronger impact on endothelial-cell density than VEGFR2 silencing (Figure 4c). These findings correlated with a two- to threefold increase in apoptosis of serum-starved, VEGFR1-knockdown endothelial cells, while VEGFR2 knockdown had no effect on cell survival (Figure 4d). To confirm these data using a second apoptotic assay, we analyzed the activity of the effector of apoptosis caspase-3 (Figure $4 f$ and $g$ ). We observed that VEGFR1, but not VEGFR2, knockdown is sufficient to enhance caspase-3 activity in starved endothelial cells (Figure $4 \mathrm{f}$ and $\mathrm{g}$ ). Knockdown of either VEGFR1 or VEGFR2 did not have any effect on endothelialcell cycle (Figure 4e). Notably, with complete endothelial-cell medium ( $5 \%$ FBS), we observed a decrease in capillary tube formation only when VEGFR2 expression was knocked down in endothelial cells (Figure $4 \mathrm{~h}$ and i). However, under a low serum concentration (2.5\%), downregulation of either receptor led to significant inhibition of capillary tube formation (Figure $4 \mathrm{~h}$ and i). Together, these data demonstrate that while VEGFR1 signaling primarily regulates endothelial-cell survival, VEGFR2 signaling is involved in vascular differentiation and capillary-like tube formation.

VEGF was shown to enhance endothelial-cell survival by inducing the expression of $\mathrm{Bcl}-2$ (Figure $5 \mathrm{a}$ ). ${ }^{25}$ We observed that VEGFR1 signaling is required for VEGF-induced upregulation of $\mathrm{Bcl}-2$ expression in endothelial cells (Figure $5 \mathrm{~b}$ ).

\footnotetext{
Figure 2 VEGFR1 is localized in the nucleus of endothelial cells, while VEGFR2 undergoes endocytosis and nuclear translocation upon exposure to VEGF. (a, $\mathbf{b})$ Serumstarved HDMECs were treated with $50 \mathrm{ng} / \mathrm{ml} \mathrm{EGF,} 50 \mathrm{ng} / \mathrm{ml} \mathrm{VEGF}_{165}, 20 \mathrm{ng} / \mathrm{ml} \mathrm{IL-6}$, or left untreated for $1 \mathrm{~h}$. RT-PCR (a) and real-time PCR (b) were performed to evaluate VEGFR1 and VEGFR2 mRNA expression levels. Data for real-time PCR were normalized against untreated controls. (c) Representative confocal microscopy images of VEGFR1 and VEGFR2 in untreated HDMECs or HDMECs exposed to $50 \mathrm{ng} / \mathrm{ml} \mathrm{rhVEGF}_{165}$ for $30 \mathrm{~min}$. VEGFR1 and VEGFR2 were detected with FITC-conjugated antibodies (green color), and DAPI was used for identification of cell nuclei (blue color). The exposure time for the panels depicting VEGFR2 expression in VEGF-treated HDMECs was increased to allow for visualization of the staining and evaluation of the cellular localization of this receptor. (d-f) VEGFR1 and VEGFR2 sub-cellular distribution (CE, cytoplasmic/cell membrane extract; NE, nuclear extract) were detected by cell fractionation followed by Western blots. GAPDH was used as control for the cytoplasmic/ cell membrane fraction, and hnRNP as control for the nuclear fraction. (d) HDMECs were treated with 0 or $50 \mathrm{ng} / \mathrm{ml} \mathrm{VEGF}{ }_{165}$ for 30 min. (e) HDMECs were treated with $50 \mathrm{ng} / \mathrm{ml} \mathrm{EGF}, 50 \mathrm{ng} / \mathrm{ml} \mathrm{rhVEGF}{ }_{165}, 20 \mathrm{ng} / \mathrm{ml} \mathrm{IL-6}$, or left untreated for $30 \mathrm{~min}$. Expression of phospho-STAT3 in HDMECs treated with IL-6 was used as positive control for nuclear translocation. (f) Starved HDMECs were pre-incubated with the inhibitor of endocytosis, Con-A, for $30 \mathrm{~min}$, and then treated with $50 \mathrm{ng} / \mathrm{ml} \mathrm{VEGF}{ }_{165} \mathrm{in}$ the presence of $5 \mu \mathrm{g} / \mathrm{ml}$ Con-A for additional $30 \mathrm{~min}$. (g) HDMECs were starved overnight and treated with $50 \mathrm{ng} / \mathrm{ml} \mathrm{VEGF}_{165}$ for $20 \mathrm{~min}$ to induce VEGFR2 translocation. VEGFR2 was deglycosylated with an enzyme cocktail constituting PNGase, sialidase, O-glycosidase, $\beta$-galactosidase, and glucosaminidase. Western blotting with rabbit anti-VEGFR2 antibody was performed with both NE and CE extracts
} 
Surprisingly, VEGFR2 knockdown correlated with baseline increase in Bcl-2 expression and c-Jun phosphorylation in unstimulated endothelial cells (Figure $5 c$ and d). However, VEGF does not induce Bcl-2 or phospho-c-Jun levels above baseline in VEGFR2-knockdown HDMECs (Figure 5c and d). JNK-c-Jun signaling is known to control the expression of proteins involved in the regulation of cell survival. ${ }^{26}$ Here, we observed that blockade of c-Jun phosphorylation inhibited
VEGF-induced $\mathrm{Bcl}-2$ expression, survival, and the angiogenic potential of HDMECs (Figure $5 \mathrm{e}-\mathrm{g}$ ).

It is known that STAT3 (signal transducer and activator of transcription-3), Akt, and ERK mediate survival and differentiation signals in endothelial cells. ${ }^{27-29}$ We observed that the basal levels of phosphorylation of STAT3 and Akt are reduced in VEGFR1-knockdown endothelial cells, but not in VEGFR2-knockdown cells (Figure $5 \mathrm{~h}$ and i). Notably, VEGF's a

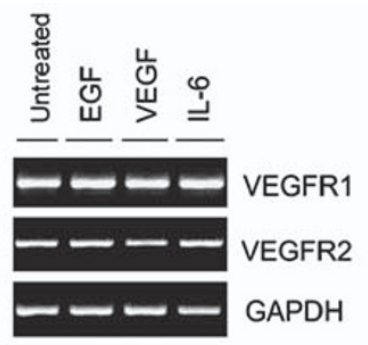

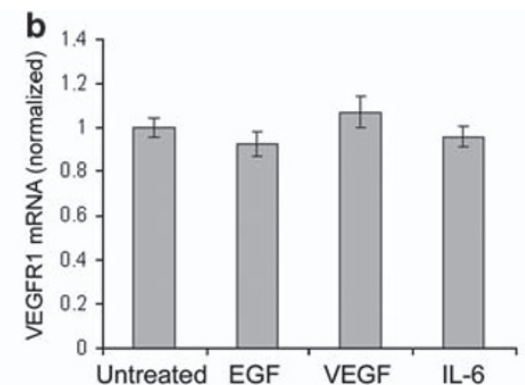
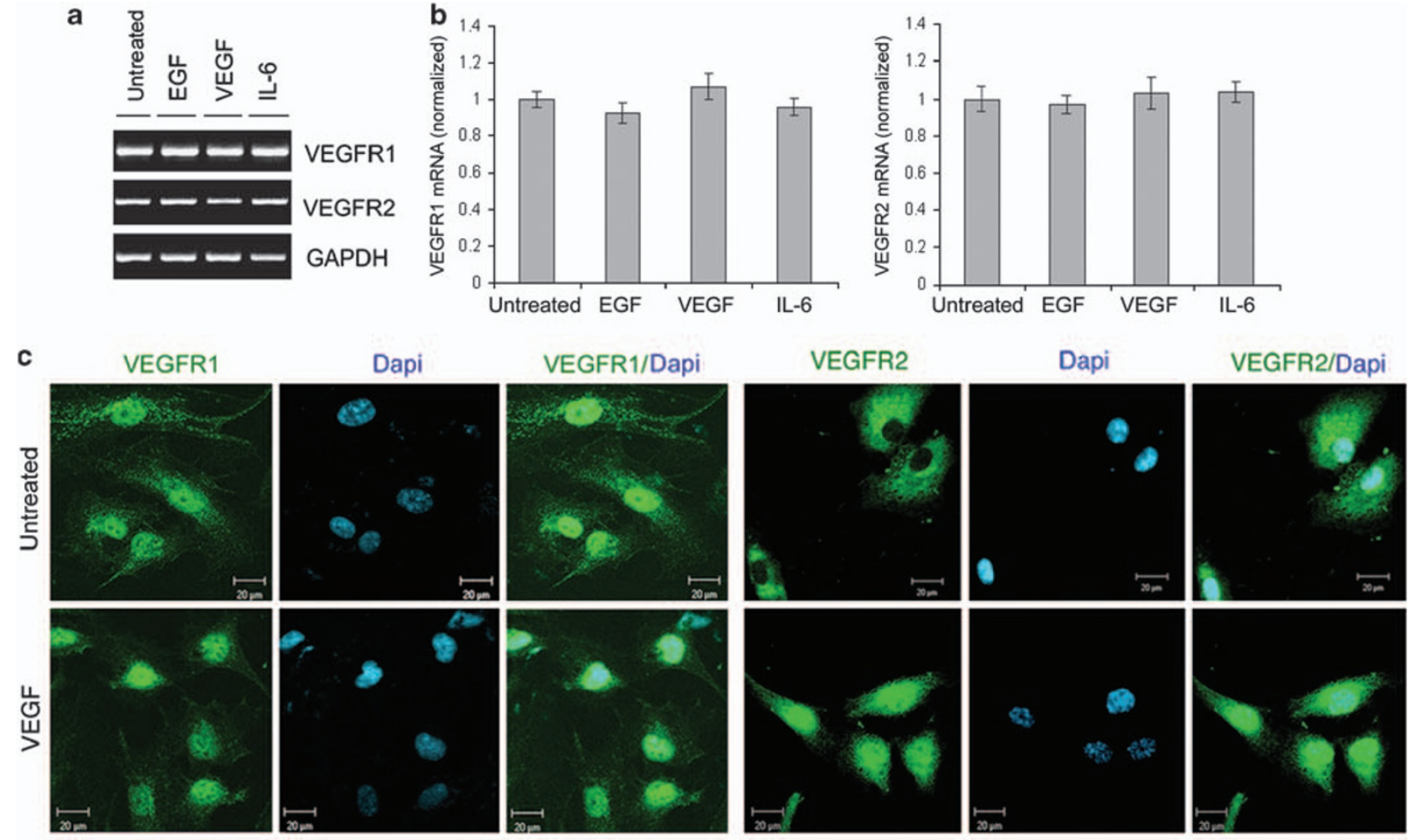

d
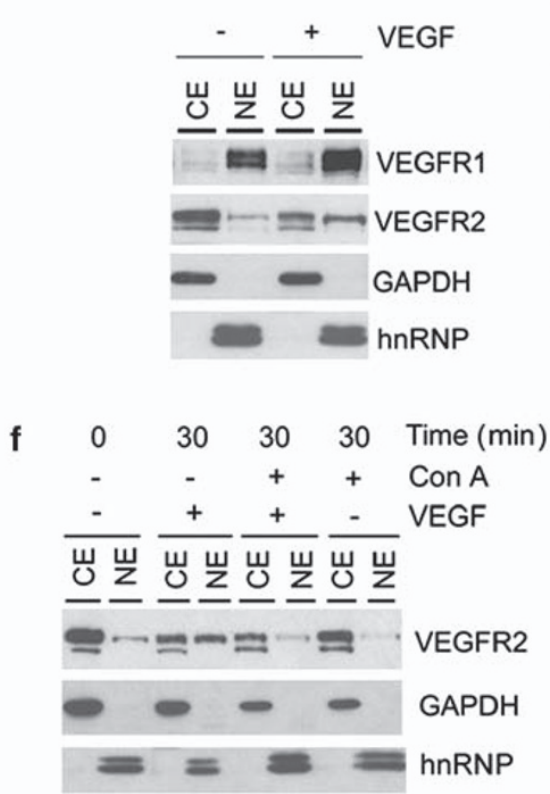

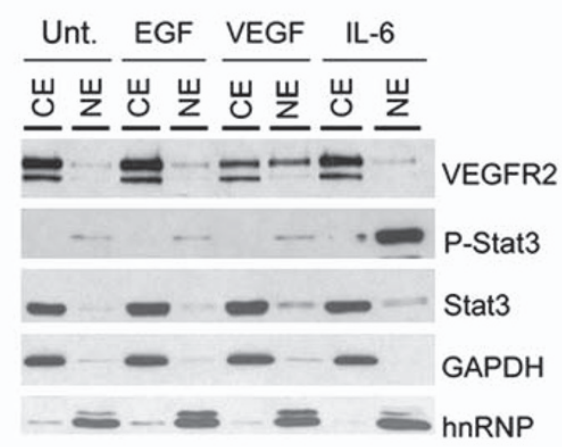

g

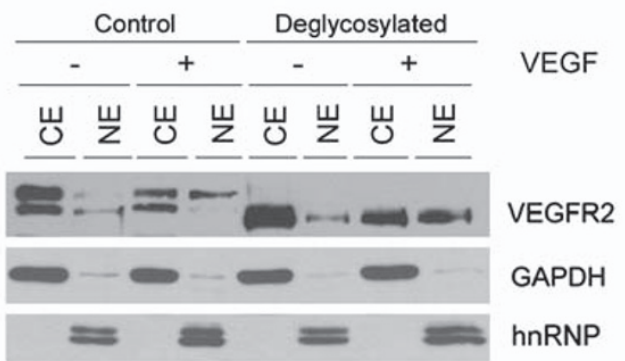


ability to induce Akt phosphorylation involves signaling through VEGFR1 (Figure 5h). VEGFR1 knockdown (but not VEGFR2) increased the basal levels of phosphorylated ERK (Figure 5h). VEGFR1 knockdown further enhanced the induction of ERK phosphorylation in response to a 15-min exposure to VEGF, as compared with vector control endothelial cells treated with VEGF (Figure 5h). However, the level of ERK phosphorylation in response to VEGF in VEGFR2-knockdown cells was similar (shRNA-VEGFR2a), or lower (shRNA-VEGFR2b), than that in the control cells (Figure 5i). Knockdown of either VEGFR1 (data not shown) or VEGFR2 had no effect on EGF-mediated signaling, confirming the specificity of the responses to VEGF (Figure 5j). Functional assays revealed that PI3K/Akt signaling is required for capillary tube formation (Supplementary Figure 3). STAT3 inhibition mediated similar effects, but the decrease in the number of capillary tubes was not as pronounced. In contrast, blockade of ERK1/2 signaling inhibited capillary tube formation without a comparable decrease in cell number (Supplementary Figure 3). Together, these data demonstrated that VEGFR1 signaling is involved in the regulation of STAT3 and Akt homeostatic activity, which have been shown to be required for endothelial-cell survival. ${ }^{30,31}$ On the other hand, VEGF signals through VEGFR2 to activate ERK1/2, which is required for capillary tube formation. ${ }^{29}$

Bevacizumab normalizes VEGFR1 and VEGFR2 protein
levels in tumor-associated endothelial cells. To evaluate
the mechanisms underlying the regulation of VEGFR1
and VEGFR2 protein levels mediated by tumor cells
in vitro, HDMECs were exposed to conditioned medium (CM)
of VEGF-expressing human squamous-cell carcinoma
cells (UM-SCC-1) (Figure 6a). The expected increase in
endothelial-cell number and capillary tube formation
mediated by UM-SCC-1 CM correlated with upregulation of
VEGFR1 and downregulation of VEGFR2 (Figure $6 \mathrm{~b}-\mathrm{d}$ ).
UM-SCC-1 CM induced phosphorylation of c-Jun, Akt,
ERK1/2, and STAT3, and upregulation of Bcl-2 expression,
in endothelial cells (Figures $6 \mathrm{~d}-\mathrm{f}$ and 7c). VEGFR1 signaling
participates in UM-SCC-1-induced phosphorylation of STAT3
and Akt, but not in ERK1/2 phosphorylation (Figure $6 \mathrm{f}$ ). In
contrast, VEGFR2 signaling is involved in UM-SCC-1-
induced ERK1/2 phosphorylation, but has no effect on
STAT3 and Akt activity (Figure $6 \mathrm{~g}$ ).
To understand the effect of VEGF on the regulation of
VEGFR1 and VEGFR2 in tumor-associated endothelial cells,
we used the humanized anti-VEGF monoclonal antibody bevacizumab (Avastin) that is approved for treatment of several cancers. ${ }^{3}$ In absence of FBS, bevacizumab had no effect on VEGFR1 or VEGFR2 protein levels (Figure 7a). Bevacizumab inhibited the effect of FBS or tumor-cell CM (UM-SCC-1 and OSCC3), and restored the baseline levels of VEGFR1, VEGFR2, and Bcl-2 in human endothelial cells in vitro (Figure $7 b$ and $c$ and Supplementary Figure 4). To evaluate the effect of bevacizumab on VEGFR1 and VEGFR2 protein levels in vivo, we engineered human tumors vascularized with human blood vessels in immunodeficient mice, as described. ${ }^{32,33}$ UM-SCC-1 cells were selected because they express high levels of VEGF (Figure 6a), but have undetectable levels of VEGFR1 or VEGFR2 (Figure 7d). The antiangiogenic effect of $15 \mathrm{mg} / \mathrm{kg}$ bevacizumab (Figure $7 \mathrm{f}$ and $\mathrm{g}$ ) correlated with the normalization of VEGFR expression levels within the tumors, that is, downregulation of VEGFR1 and upregulation of VEGFR2 (Figure 7e).

\section{Discussion}

The understanding of mechanisms underlying VEGF signaling has become critically important in recent years due to the increasing use of therapeutic inhibitors of this pathway for the treatment of cancer. It has become evident that whereas some patients benefit from such therapy, a significant subset of patients is refractory to treatment. This might be due to development of evasive resistance to VEGF inhibition by 'turning on' of alternative angiogenic pathways, or by enhancement of recruitment of circulating endothelial progenitor cells. ${ }^{11,34,35}$ In both cases, activity and regulation of VEGFR signaling pathways play a critical role.

We observed that recombinant human VEGF, FBS, or conditioned medium from VEGF-expressing tumor-cell lines induce a 'rheostat-like' pattern of regulation of VEGFRs, enhancing VEGFR1 while decreasing VEGFR2 protein levels in primary endothelial cells. Notably, sub-cellular distribution of VEGFR1 and VEGFR2 is fundamentally different. Our studies demonstrate that VEGFR1 is found primarily in the nucleus and does not move from there upon stimulation with VEGF. Of note, in a recent study, the presence of VEGFR1 in the Golgi of human umbilical vein endothelial cells (HUVECs) was demonstrated by fluorescence microscopy. ${ }^{36}$ The data presented here do not exclude the possibility that some VEGFR1 can be found in the cytoplasmic fraction of HDMECs. However, our cell fractionation and confocal microscopy studies demonstrated unequivocally that the majority of VEGFR1 is present in the nucleus. In contrast,

\footnotetext{
Figure 3 Signaling pathways required for VEGF-induced inverse regulation of VEGFR1 and VEGFR2 in primary endothelial cells. (a) Starved HDMECs were pretreated with $5 \mu \mathrm{M}$ ubiquitin aldehyde inhibitor (Ub) or $10 \mu \mathrm{M}$ proteasome inhibitor MG132 for $1 \mathrm{~h}$, and then treated with $50 \mathrm{ng} / \mathrm{ml}$ VEGF for 30 min in the presence of Ub or MG132. VEGFR2 expression was detected by Western blotting. (b) Cell fractionation was used to determine the sub-cellular distribution of VEGFR2 in HDMECs treated with $50 \mathrm{ng} / \mathrm{ml}$ VEGF $_{165}$ in the presence of Ub or MG132. (c-g) Western blots to evaluate the effect of JNK-c-Jun signaling on the expression of VEGFR1 and VEGFR2. (c, d) HDMECs were exposed to $50 \mathrm{ng} / \mathrm{ml} \mathrm{VEGF}_{165}$ for the time periods indicated (c), or for $1 \mathrm{~h}$ (d). HDMECs (e, g) or HPECs (f) were preincubated for $1 \mathrm{~h}$ with $10 \mu \mathrm{M} \mathrm{JNK}$ inhibitor SP600125, followed by treatment with $50 \mathrm{ng} / \mathrm{ml} \mathrm{VEGF}_{165}$ in the presence of SP600125. (h) Starved HDMECs were treated with $10 \mu \mathrm{M} \mathrm{MG132}$ for $2 \mathrm{~h}$. Sub-cellular distribution of VEGFR1 was detected by Western blotting. (i) HDMECs were pretreated with $5 \mu \mathrm{M} \mathrm{Ub}$ for $1 \mathrm{~h}$ and treated with $50 \mathrm{ng} / \mathrm{ml} \mathrm{VEGF}_{165}$ in the presence of Ub for $30 \mathrm{~min}$. VEGFR1 expression was detected by Western blots. (j) HDMECs were treated with $50 \mathrm{ng} / \mathrm{ml} \mathrm{VEGF} 165$ for the indicated time periods. Western blots were performed for VEGFR1, VEGFR2, phospho-Akt, Akt, phospho-ERK1/2, and ERK1/2. (k, I) HDMECs were preincubated with $20 \mu \mathrm{M} \mathrm{LY294002} \mathrm{(k)} \mathrm{or} 20 \mu \mathrm{M}$ PD98059 (I) for $1 \mathrm{~h}$, followed by treatment with $50 \mathrm{ng} / \mathrm{ml} \mathrm{VEGF}_{165}$ in the presence of inhibitors for the indicated time periods. Western blots were performed to evaluate VEGFR1, VEGFR2, phospho-Akt, Akt, phosphoERK1/2, and ERK1/2 expression
} 
a

d

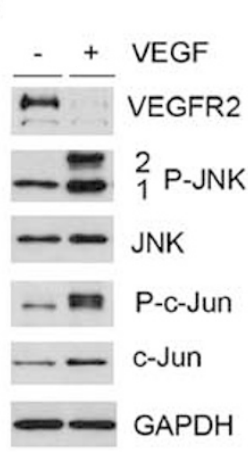

e

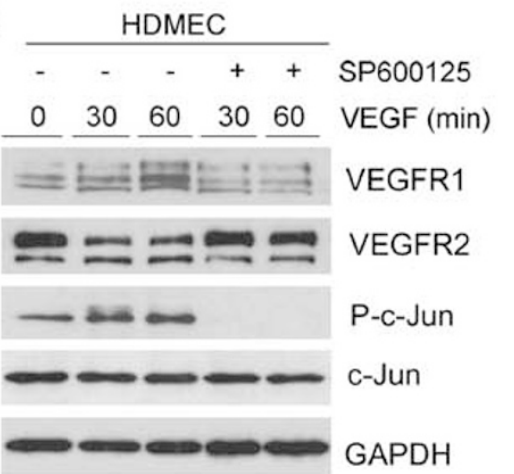

Ub inhibitor MG132 VEGF

c

01530 60 VEGF $(\mathrm{min})$

$\geq 2+2=4$ VEGFR1

VEGFR2

P-C-Jun

는 : : : VEGFR2

$-2=$ P-C-Jun

C-Jun

GAPDH

C-Jun

GAPDH

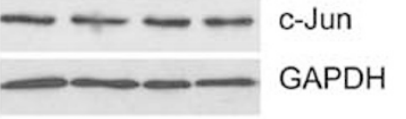

\section{$\approx \equiv \mathrm{hnRNP}$}

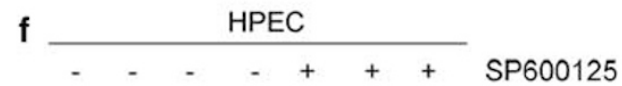

$0 \quad 15 \quad 30 \quad 60 \quad 15 \quad 30 \quad 60 \operatorname{VEGF}(\mathrm{min})$

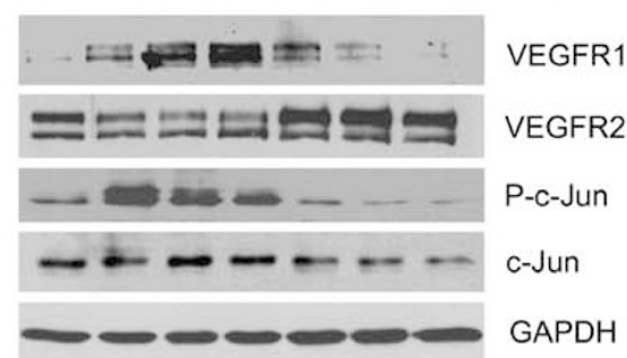

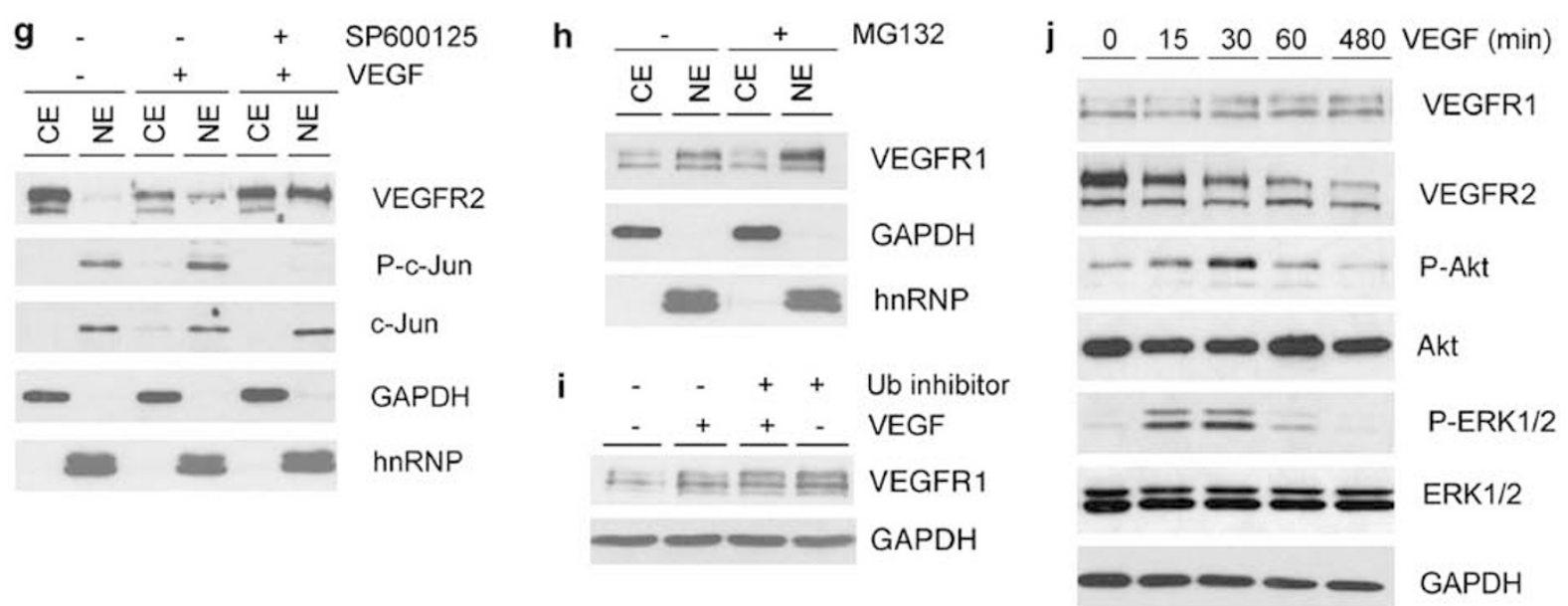

k

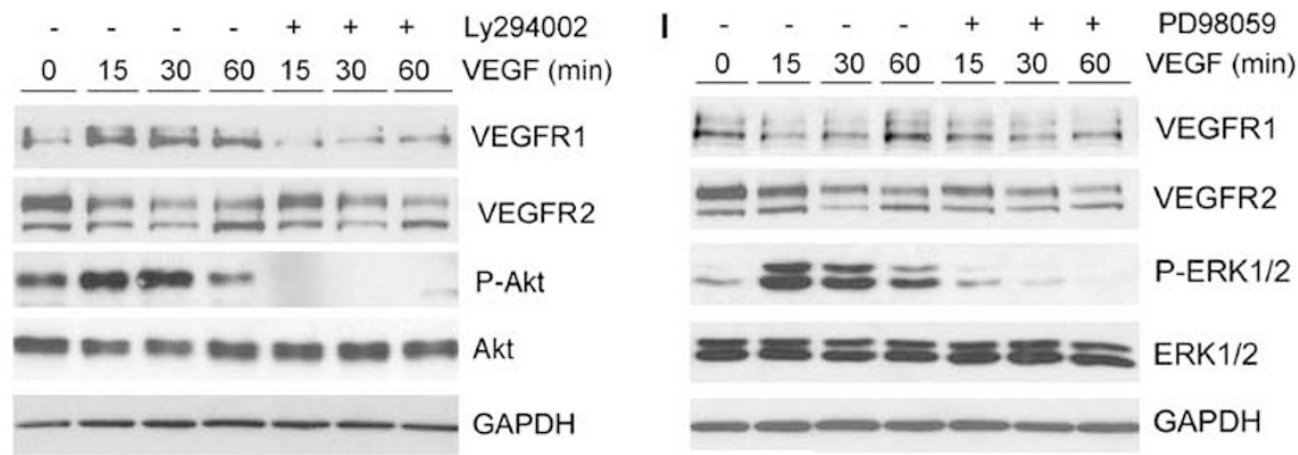


VEGFR2 clearly changes location from the cell membrane/ cytoplasmic fraction to the nucleus when endothelial cells are treated with VEGF. Western blots for VEGFR2 typically show two bands (representing two isoforms) in unstimulated endothelial cells. However, upon stimulation with VEGF we observed that only the larger isoform is translocated to the nucleus. The most significant decrease in expression mediated by VEGF is observed with the larger isoform, through mechanisms that are currently under investigation in our laboratory. Notably, blockade of endocytosis prevented VEGF-induced nuclear translocation of VEGFR2, but did not prevent its downregulation. In contrast, inhibition of the ubiquitin-proteasome system prevented VEGF-induced VEGFR2 downregulation, but did not prevent nuclear translocation. These data suggest that the processes of nuclear translocation and VEGFR2 downregulation are mechanistically independent.

It is known that JNK targets the ubiquitination of regulatory proteins, including ATF2. ${ }^{23}$ We observed here that VEGF induced potent activation of the JNK-C-Jun pathway, and that JNK activity is associated with ubiquitination of VEGFR2. On the other hand, inhibition of the ubiquitin or proteasome activity is sufficient to enhance the expression of VEGFR1 in primary endothelial cells. These findings suggest that endothelial cells are continuously synthesizing VEGFR1 and that ubiquitin-proteasome activity is necessary to maintain its homeostatic levels. Notably, regulation of VEGFR1 protein levels is dependent on Akt and ERK1/2 phosphorylation. Since these two kinases typically inhibit the degradation of proteins by the ubiquitin-proteasome system, we postulate that VEGF induces phosphorylation of Akt and ERK1/2, which in turn prevents degradation of VEGFR1 by the ubiquitinproteasome system. Collectively, these data suggest that VEGF orchestrates an intricate process mediated by the Akt/ ERK and JNK/c-Jun that protects VEGFR1 while 'tagging' VEGFR2 for degradation, leading to rapid reversal of the protein levels of these two receptors. We propose that this mechanism is involved in the well-characterized ability of the vascular endothelium to quickly adapt to sudden changes in the microenvironment.

We and others have reported that VEGF enhances the survival of endothelial cells by regulating the activity of the antiapoptotic Bcl-2 and inhibiting caspase-mediated cell death. ${ }^{25,37}$ At that time, it was believed that this process was mediated by VEGFR2 signaling. The availability of specific shRNA constructs to selectively downregulate the expression of each VEGFR allowed us to revisit these data. We demonstrate here that endothelial-cell survival is regulated primarily by VEGFR1 signaling, while VEGFR2 signaling regulates the differentiation of endothelial cells into capillary tubes.

Our ability to discriminate the function of VEGFR1 and VEGFR2 in vivo is hindered by the fact that both receptors play critical and complementary roles in angiogenesis. ${ }^{38,39}$ However, in attempt to validate the concepts tested here within relevant tumor models, we exposed the endothelial cells to the CM of VEGF-producing squamous-cell carcinomas. As expected, the tumor cells enhanced the survival and angiogenic potential of endothelial cells. This was correlated with increase in the expression of VEGFR1, Bcl-2, and phospho-c-Jun, which is consistent with the increase in the survival typically observed in tumor-associated endothelial cells. $^{25}$

The inhibition of tumor angiogenesis mediated by VEGF signaling blockade with bevacizumab correlated with a reversal in VEGFR1 and VEGFR2 protein levels. These data present the intriguing hypothesis that the antitumor effect of anti-VEGF therapies requires normalization of VEGFR1 and VEGFR2 protein levels. This work suggests that the process of normalization of VEGFR1/VEGFR2 can potentially constitute a novel conceptual target for cancer treatment. Moreover, the reversal of VEGFR1 and VEGFR2 can potentially be useful as a molecular biomarker for the effectiveness of anti-VEGF therapies.

Collectively, our studies demonstrated that VEGFR1 is the dominant receptor in the tumor microenvironment, and that VEGFR1 is required for endothelial-cell survival. These findings support the concept that VEGFR1 is the preferable therapeutic target in cancer. However, the unexpected finding that this receptor is localized in the nucleus of angiogenic endothelial cells suggests that highly permeable drugs are required to achieve clinically relevant inhibition of VEGFR1 signaling in vivo. Moreover, this work revealed a novel mechanism by which a ligand inversely regulates two receptors to promote angiogenesis. Inversely reciprocal regulation of receptors by a single ligand might be a common mechanism shared by cells to regulate the function of other ligand/receptor systems in physiology and in disease.

Materials and Methods
Cell culture and reagents. Primary HDMECs (Cambrex, Walkersville, MD,
USA) and primary HPECs (Cambrex) were cultured in endothelial growth medium-2
for microvascular cells (EGM2-MV; Cambrex). Head and neck squamous-cell
carcinoma cells (UM-SCC-1 and UM-SCC-11B, gift from T Carey, University of 
Michigan; OSCC3, gift from M Lingen, University of Chicago) were cultured in Dulbecco's modified Eagle's medium (DMEM, Invitrogen, Carlsbad, CA, USA) supplemented with $10 \% \mathrm{FBS}, 100 \mathrm{U} / \mathrm{ml}$ penicillin, and $100 \mu \mathrm{g} / \mathrm{ml}$ streptomycin. HDMECs and UM-SCC- 1 cells were starved overnight and treated with $0-50 \mathrm{ng} / \mathrm{ml}$ rhEGF, 0-50 ng/ml rhVEGF ${ }_{165}$, or 0-50 ng/ml rhPIGF (R\&D Systems, Minneapolis,
MN, USA), 0-50 ng/ml rhVEGF-E (Fitzgerald, Concord, MA, USA), or $0-20 \mathrm{ng} / \mathrm{ml}$ rhIL-6 (Biosource, Camarillo, CA, USA) for the indicated time points. Alternatively, HDMECs were treated with $0-5 \mu \mathrm{g} / \mathrm{ml}$ goat anti-human VEGF antibody (R\&D Systems), 0-20 $\mu$ M LY294002 (PI3K inhibitor; AG Scientific Inc., San Diego, CA, USA), 0-30 $\mu \mathrm{M}$ PD98059 (MEK-1 inhibitor, upstream of ERK1/2; Cell Signaling

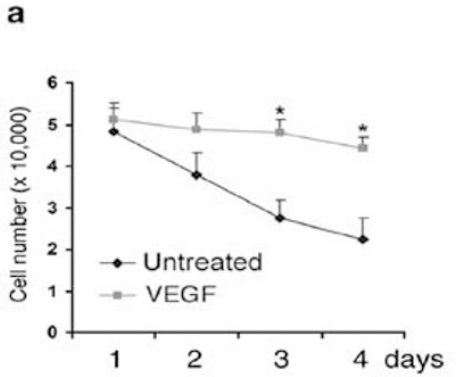

b VEGFR1

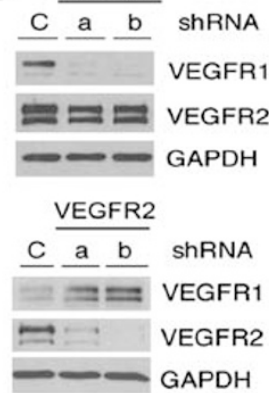

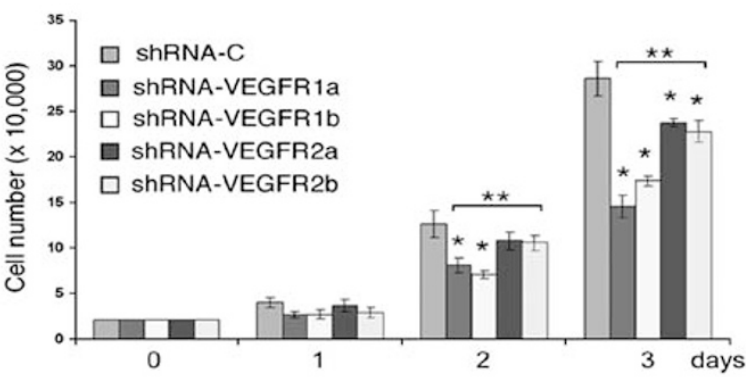

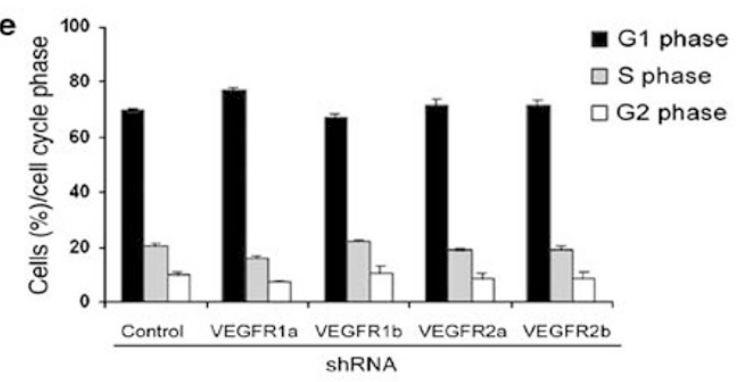

d
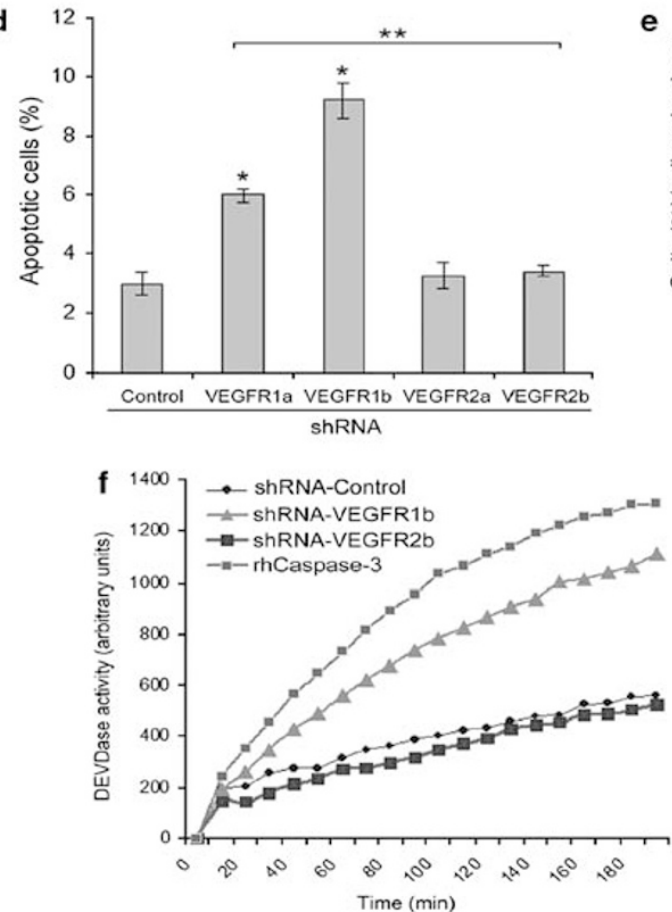

g

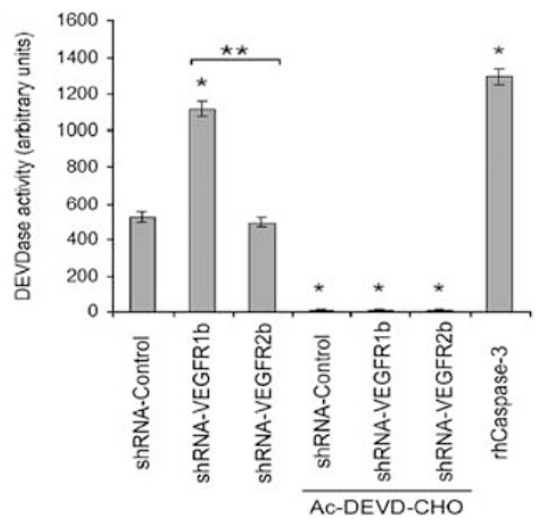

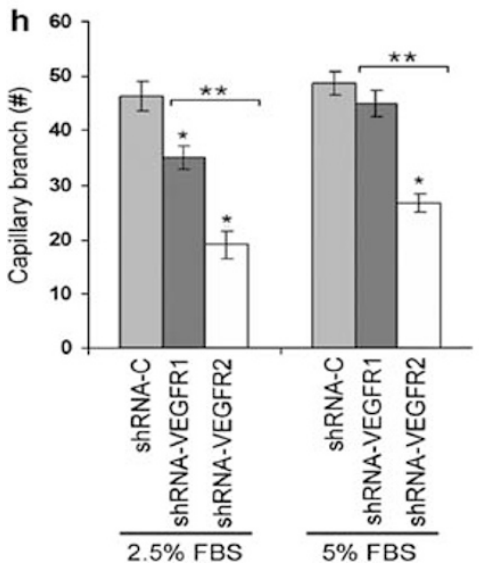

i ShRNA-C

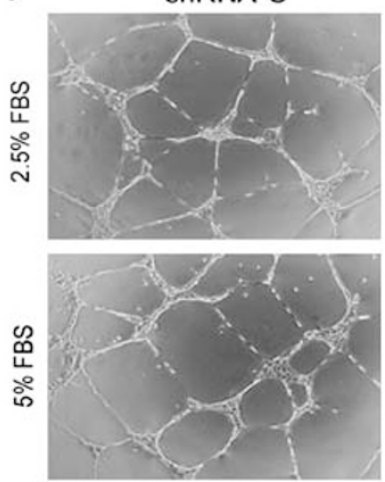

ShRNA-VEGFR1

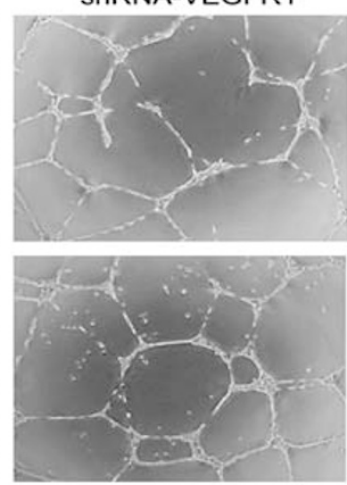

shRNA-VEGFR2

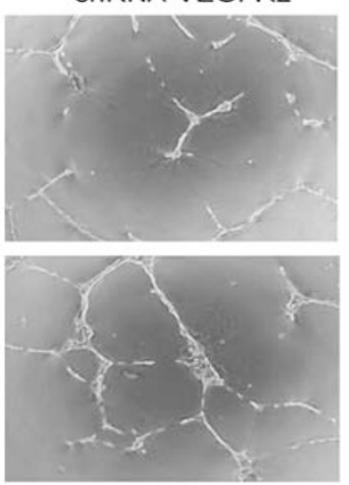




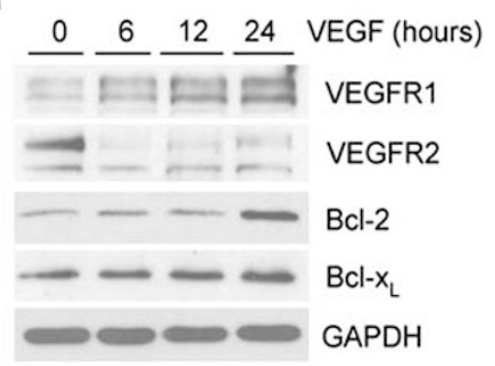

b

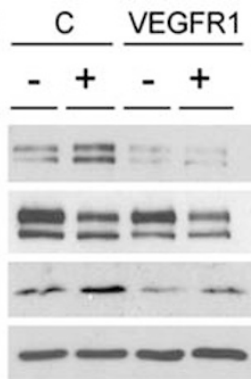

ShRNA

VEGFR1

VEGFR2

$\mathrm{Bcl}-2$

GAPDH
C

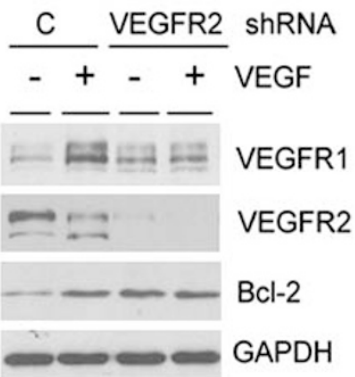

d

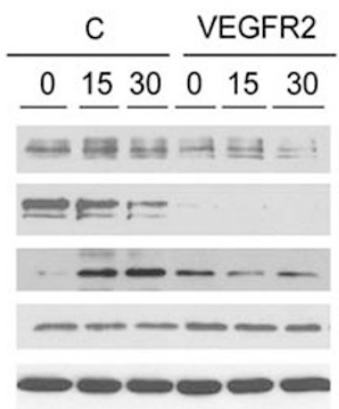

shRNA

VEGF (min)

VEGFR1

VEGFR2

P-C-Jun

C-Jun

GAPDH

e

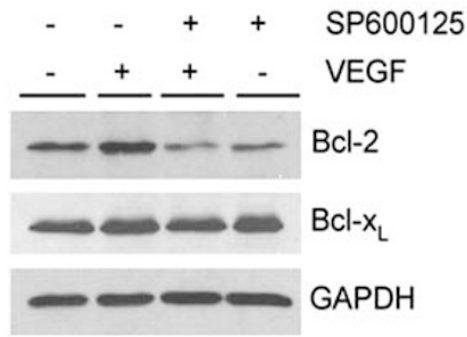

g

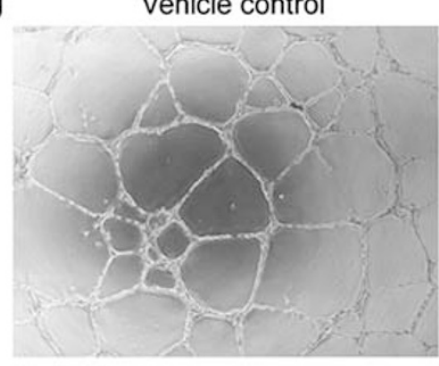

SP600125

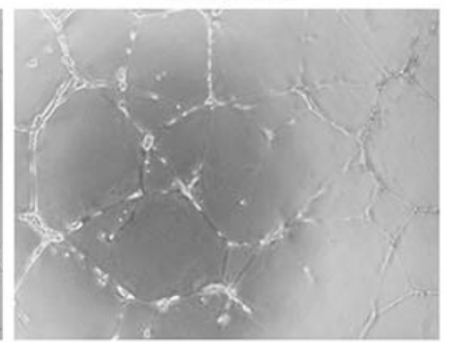

h

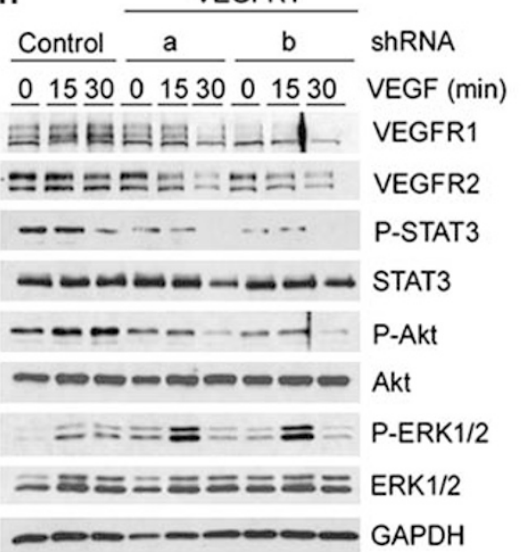

i

\begin{tabular}{|c|c|c|c|}
\hline \multirow[b]{2}{*}{ Control } & & & \multirow[b]{2}{*}{ shRNA } \\
\hline & a & b & \\
\hline$\underline{0} 15 \underline{30}$ & $0 \underline{15} \underline{30}$ & 01530 & VEGF (min) \\
\hline 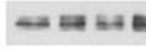 & $m a$ & $-4=4=4$ & VEGFR1 \\
\hline$\Leftrightarrow E$ & -- & $\ldots$ & VEGFR2 \\
\hline$-\cdots$ & $-\cdots$ & $--\cdots$ & P-STAT3 \\
\hline$-\infty-\infty$ & --2 & 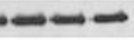 & STAT3 \\
\hline$-\cdots==$ & $E==$ & $= \pm=-$ & P-Akt \\
\hline$-\infty \cdot$ & 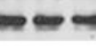 & 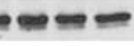 & Akt \\
\hline$=-$ & $=$ & $=$ & P-ERK1/2 \\
\hline 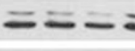 & $===$ & $E=-$ & - ERK1/2 \\
\hline
\end{tabular}

j

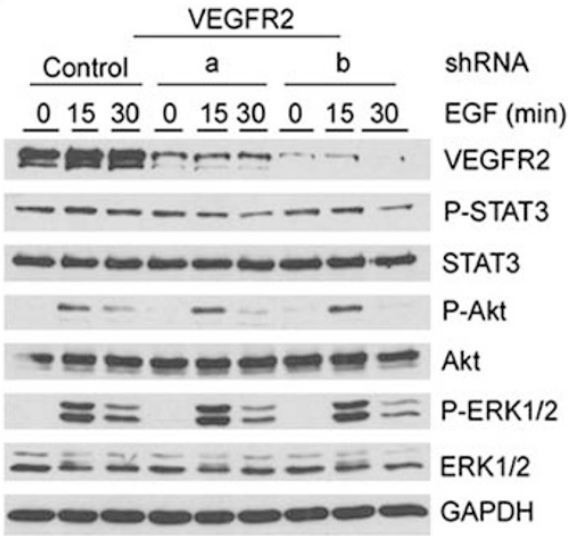

Figure 5 VEGF signals through the JNK-C-Jun axis to induce Bcl-2 and enhance the angiogenic potential of endothelial cells. (a) Starved HDMECs were incubated with $50 \mathrm{ng} / \mathrm{ml}$ VEGF for the indicated time periods. VEGFR1, VEGFR2, and Bcl-2 expression was determined by Western blotting. (b, c) HDMECs stably transduced with shRNA-VEGFR1 (b) or shRNA-VEGFR2 (c) were cultured with $50 \mathrm{ng} / \mathrm{ml} \mathrm{VEGF}{ }_{165}$ for $24 \mathrm{~h}$. VEGFR1, VEGFR2, and Bcl-2 expression was detected by Western blotting. (d) HDMECs stably transduced with shRNA-VEGFR2 were treated with $50 \mathrm{ng} / \mathrm{ml} \mathrm{VEGF}_{165}$ for the indicated time periods. Phospho-c-Jun and c-Jun expression levels were detected by Western blotting. (e) HDMECs were preincubated with $5 \mu \mathrm{M} \mathrm{SP} 600125$ for $1 \mathrm{~h}$, then treated with $50 \mathrm{ng} / \mathrm{ml}$ VEGF in the presence of SP600125, overnight. Bcl-2 and Bcl- $x_{L}$ expression levels were detected by Western blotting. (f) Graph depicting the number of capillary branches and $(g)$ representative photomicrographs $(\times 40)$ of HDMECs cultured in the presence of 0 or $5 \mu \mathrm{M} \mathrm{SP} 600125$ for $24 \mathrm{~h}$. Data are represented as mean \pm S.D. from three independent experiments. The asterisk indicates $P<0.05$. VEGFR1 signaling is required for maintaining basal activity of STAT3 and Akt, while VEGFR2 is required for VEGF-induced ERK phosphorylation in endothelial cells. (h-j) HDMECs stably transduced with shRNA-VEGFR1 (h), shRNA-VEGFR2 (i, j), or control shRNA-C were cultured in medium supplemented with $50 \mathrm{ng} / \mathrm{ml} \mathrm{VEGF}{ }_{165}$ (h, i) or $50 \mathrm{ng} / \mathrm{ml}$ EGF (j). Phospho-STAT3, STAT3, phospho-Akt, Akt, phospho-ERK1/2, and ERK1/2 expression levels were detected by Western blots 


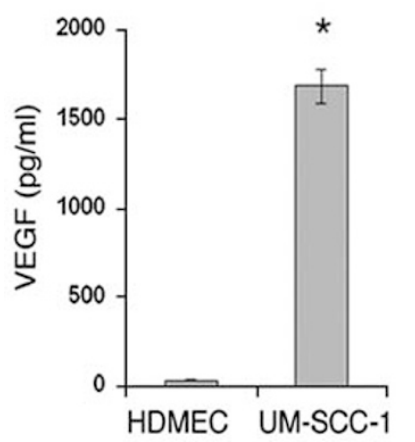

b

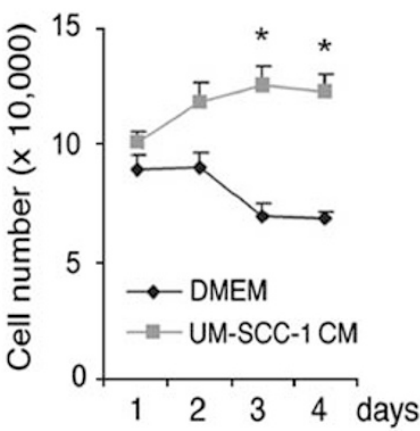

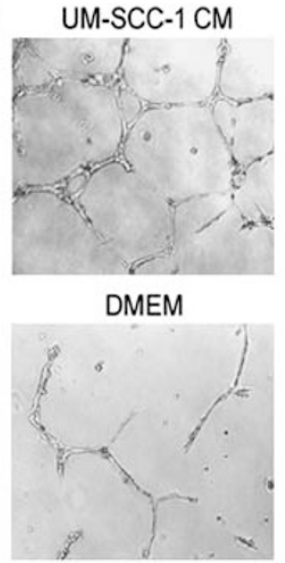

d UM-SCC-1 CM

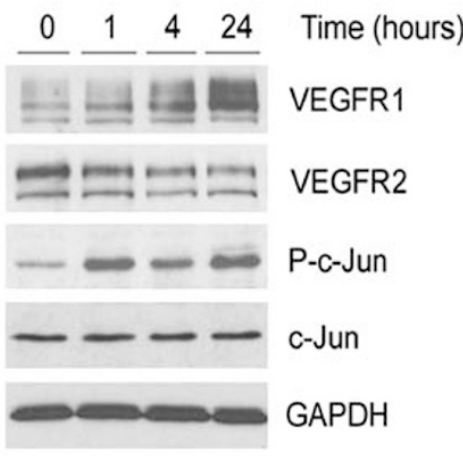

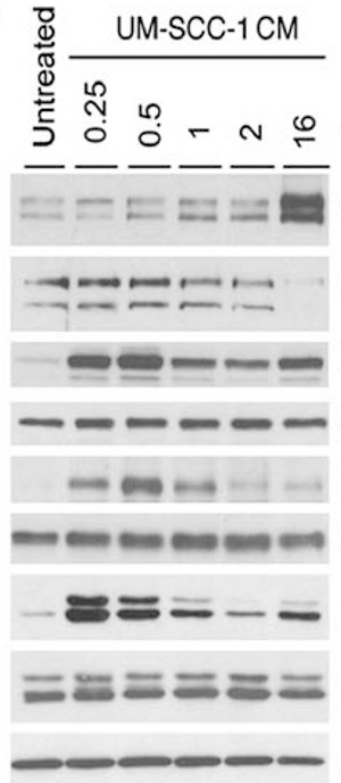

f

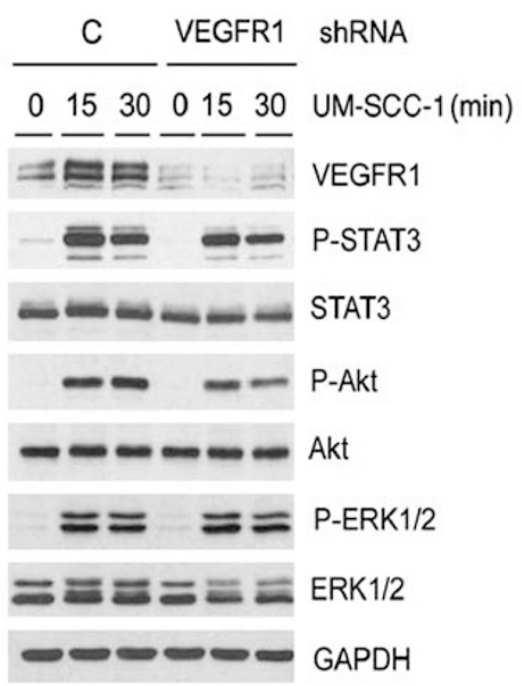

g

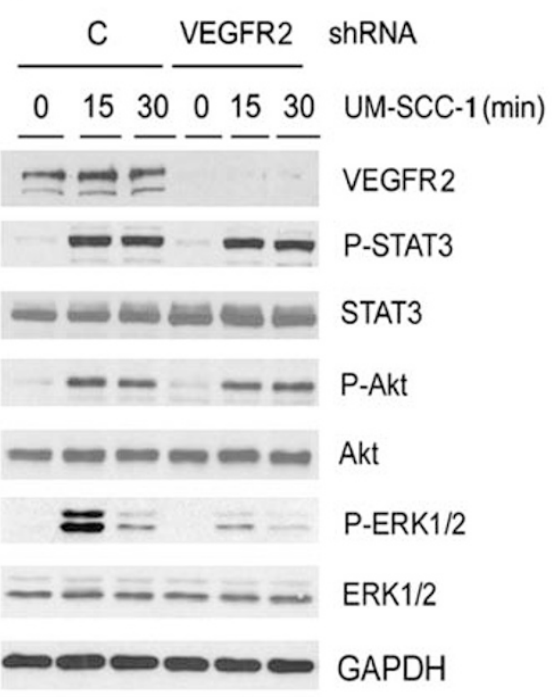

Figure 6 Effect of the growth-factor milieu secreted by squamous-cell carcinomas on VEGFR1 and VEGFR2 expression and signaling in endothelial cells. (a) ELISA for secreted VEGF ${ }_{165}$ in HDMECs and UM-SCC-1 cells. (b) Graph depicting the number of cells when HDMECs were cultured with UM-SCC-1 CM (no FBS) or with control medium (DMEM; no FBS). (c) Capillary tube assay with HDMECs cultured in low-growth-factor Matrigel for $24 \mathrm{~h}$. HDMECs were cultured with UM-SCC-1 CM or control DMEM. Representative images of capillary tubes at $\times 40$. (d) HDMECs were treated with UM-SCC-1 CM for the indicated time periods and VEGFR1, VEGFR2, phospho-C-Jun, and c-Jun expression levels were evaluated by Western blots. (e-g) HDMECs (e), HDMECs transduced with shRNA-VEGFR1 (f), HDMECs transduced with shRNA-VEGFR2 (g), or shRNA-C were starved overnight and treated with UM-SCC-1 CM for the indicated time periods. VEGFR1, VEGFR2, phospho-STAT3, STAT3, phospho-Akt, Akt, phospho-ERK1/2, and ERK1/2 levels were detected by Western blots. The asterisk indicates $P<0.05$

Technology Inc., Danvers, MA, USA), 0-10 $\mu$ M SP600125 (JNK inhibitor; AG Scientific Inc.), 0-5 $\mu \mathrm{g} / \mathrm{ml}$ anisomycin (Sigma, St Louis, MO, USA); 0-5 $\mu$ M ubiquitin aldehyde inhibitor (Upstate, Temecula, CA, USA), $0-10 \mu \mathrm{M}$ proteasome inhibitor MG132 (Sigma), and $0-10 \mu \mathrm{g} / \mathrm{ml}$ Con-A (Sigma). At indicated time points, cells were collected and Western blotting or RT-PCR was performed.

Sub-cellular fractionation. Cells were resuspended in cytoplasmic extraction buffer (Panomics, Redwood, CA, USA) containing protease inhibitors and incubated for 3 min on ice. The suspension was centrifuged at 13000 r.p.m. for 5 min at $4^{\circ} \mathrm{C}$. The supernatant was collected as cytoplasmic/cell membrane extract (CE). The nuclear extract (NE) was obtained by suspending the nuclear pellet in nuclear extraction buffer (Panomics) for $40 \mathrm{~min}$ on ice with occasional vortexing, and clarified by centrifuging at 13000 r.p.m. for $10 \mathrm{~min}$ at $4^{\circ} \mathrm{C}$. The supernatant was collected as NE.

Confocal microscopy. HDMECs were seeded in Lab-Tek chamber slides (Nalge Nunc International, Noperville, IL, USA), starved overnight, and treated with
0-50 $\mathrm{ng} / \mathrm{ml} \mathrm{rhVEGF} 165$ for $15-30 \mathrm{~min}$. Cells were fixed with methanol or $4 \%$ paraformaldehyde/PBS, treated with $3 \% \mathrm{H}_{2} \mathrm{O}_{2}$ for $10 \mathrm{~min}$, and then incubated with 1-2 $\mu \mathrm{g} / \mathrm{ml} \mathrm{rabbit} \mathrm{anti-human} \mathrm{VEGFR2} \mathrm{(Santa} \mathrm{Cruz} \mathrm{Biotechnology,} \mathrm{Santa} \mathrm{Cruz,} \mathrm{CA,}$ USA), VEGFR1 (Abcam Inc., Cambridge, MA, USA) for $1 \mathrm{~h}$ at room temperature or overnight at $4^{\circ} \mathrm{C}$. ProLong Gold anti-fade reagent with DAPI (Invitrogen) was used to identify nuclei. Images were captured with a Zeiss confocal microscope (Microscopy and Image Analysis Laboratory, University of Michigan). Here, and throughout this manuscript, data from at least three independent experiments have been analyzed to verify reproducibility of results.

In vitro capillary tube formation. A total of $5 \times 10^{4} \mathrm{HDMEC}$ s were seeded in 24-well plates (Corning Incorporated, Corning, NY, USA) coated with growth factor reduced Matrigel (BD Biosciences, Bedford, MA, USA). When indicated, UMSCC-1 CM, SP600125, AG490, Ly294002, or PD98059 were used at the concentrations described above. After $24 \mathrm{~h}$, capillary tubes were counted in random fields from three wells per condition. 
a

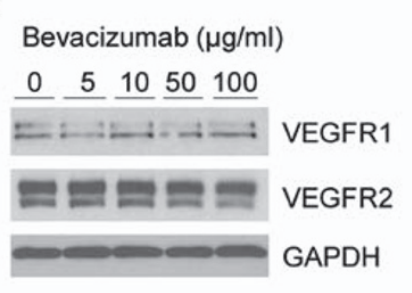

d

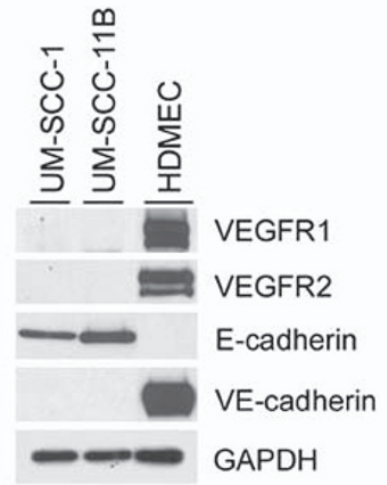

b

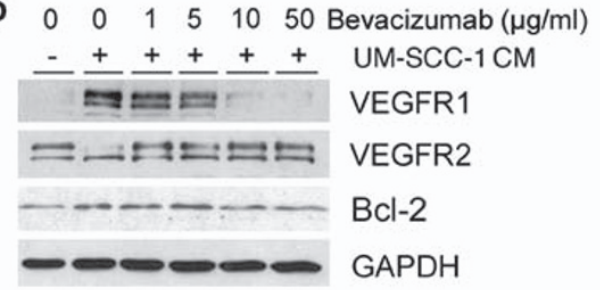

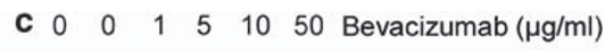

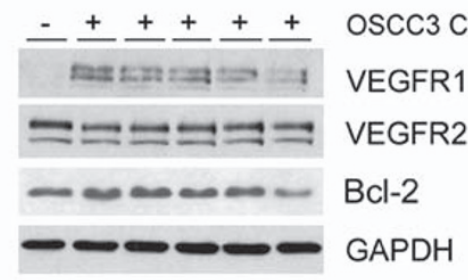

g Bevacizumab

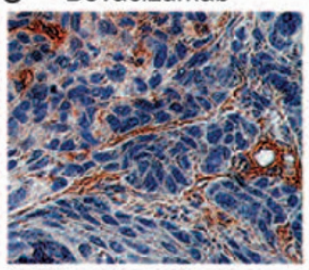

Vehicle

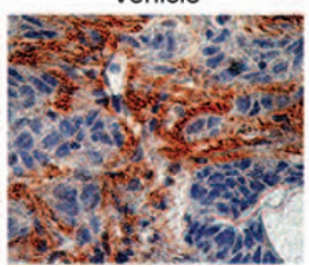

Figure 7 The antiangiogenic activity of bevacizumab correlates with the normalization of VEGFR1 and VEGFR2 expression levels in xenografted squamous-cell carcinomas. (a) HDMECs were cultured without FBS and treated with 0-100 $\mu \mathrm{g} / \mathrm{ml}$ bevacizumab for $24 \mathrm{~h}$. VEGFR1 and VEGFR2 expression was detected by Western blotting. (b, c) HDMECs were preincubated with bevacizumab for $2 \mathrm{~h}$ and then treated with UM-SCC-1 (b) or OSCC3 (c) CM for additional $24 \mathrm{~h}$ in the presence of increasing concentrations of bevacizumab. VEGFR1, VEGFR2, and Bcl-2 were detected by Western blotting. (d) The endogenous expression levels of VEGFR1 and VEGFR2 were evaluated in untreated HDMEC, UM-SCC-1, and UM-SCC-11B by Western blotting. VE-cadherin and E-cadherin were used as markers of endothelial cells and cells from epithelial origin, respectively. (e-g) Mice bearing engineered human tumors vascularized with human blood vessels received two i.p. injections of 15 or $30 \mathrm{mg} / \mathrm{kg}$ bevacizumab or vehicle control with a 1-day interval between injections. The day after completion of treatment, tumors were retrieved, homogenized, and VEGFR1 and VEGFR2 expression was evaluated by Western blotting $(\mathbf{e})$. (f) Graph depicting the number of microvessels per microscopic field $(\times 200)$ from eight tumors per experimental condition. The asterisk represents $P<0.05$. $(\mathrm{g})$ Representative photomicrographs $(\times 400)$ of tumors treated with bevacizumab or vehicle-treated controls. Tissue sections were immunostained for factor-VIII to identify blood vessels (brown, DAB-positive cells)

VEGFR1 and VEGFR2 gene silencing. HEK 293T cells were transiently co-transfected with the lentiviral packaging vectors psPAX2, pMD2.G, and shRNA-C (control), shRNA-VEGFR1, or shRNA-VEGFR2 (Vector Core, University of Michigan) by the calcium phosphate method. Supernatants containing lentiviruses were used to infect HDMECs overnight. HDMECs were selected with $1 \mu \mathrm{g} / \mathrm{ml}$ puromycin (InVivogen, San Diego, CA, USA) for at least 1 week, and downregulation of target genes was examined by Western blotting.

SCID mouse model of human tumor angiogenesis. Xenograft human tumors vascularized with human blood vessels were generated under a UCUCA-approved protocol, as described. ${ }^{32}$ Briefly, highly porous poly-L(lactic) acid (Boehringer Ingelheim, Ingelheim, Germany) scaffolds were seeded with $9 \times 10^{5}$ HDMECs and $1 \times 10^{5}$ UM-SCC-1 cells. SCID mice (CB.17.SCID; Taconic, Germantown, NY, USA) were anesthetized with ketamine and xylazine, and two scaffolds were implanted in the subcutaneous space of the dorsal region of each mouse. When tumors reached a volume of $1 \mathrm{~cm}^{3}$, mice were injected intraperitonealy twice with 15 or $30 \mathrm{mg} / \mathrm{kg}$ bevacizumab (humanized anti-VEGF monoclonal antibody; Genentech, San Francisco, CA, USA) or vehicle control, with a 48-h interval between each injection. Mice were killed the day after last injection, tumors were homogenized with Nonidet P-40 (NP-40) protein lysis buffer at $4^{\circ} \mathrm{C}$, and Western blots were performed for VEGFR1 and VEGFR2. Tumor-microvessel density was determined following identification of blood vessels by immunohistochemistry with a polyclonal anti-human factor-VIII antibody (Lab Vision, Fremont, CA, USA), as previously described. ${ }^{32}$

Western blots. Cells were lysed in $1 \%$ NP-40 lysis buffer $(50 \mathrm{mM}$ Tris- $\mathrm{HCl}(\mathrm{pH} 7.4), 200 \mathrm{mM} \mathrm{NaCl}$, and $2 \mathrm{mM} \mathrm{MgCl}_{2}$ ) containing protease inhibitors.
Membranes were incubated with the following primary antibodies for $1 \mathrm{~h}$ at room temperature or overnight at $4 \mathrm{C}$ : rabbit anti-human VEGFR1, rabbit anti-human VEGFR2, mouse anti-human phosphor-c-Jun, mouse anti-human phosphor-JNK, mouse anti-human JNK, rabbit hnRNP, mouse anti-human VE-cadherin, and rabbit anti-human E-cadherin (Santa Cruz Biotechnology); mouse anti-human phosphor STAT3, rabbit anti-human STAT3, mouse anti-human ERK1/2, rabbit anti-human phosphor-ERK1/2, rabbit anti-human phosphor-AKT, rabbit anti-human AKT, and rabbit anti-human c-Jun (Cell Signaling Technology); and mouse anti-GAPDH (Chemicon, Billerca, MA, USA), hamster anti-human Bcl-2, mouse anti-human Bcl- $x_{\mathrm{L}}$ (BD Biosciences, San Jose, CA, USA). The molecular weight for the VEGFR1 bands is approximately $200 \mathrm{kDa}$, and for the VEGFR2 bands is approximately $220 \mathrm{kDa}$. The glycosylation status of VEGFR2 was evaluated with the Enzymatic CarboRelease kit (QA-Bio, Palm Desert, CA, USA), according to the manufacturer's instructions. HDMECs were starved overnight and treated with $50 \mathrm{ng} / \mathrm{ml}$ VEGF for $20 \mathrm{~min}$. Cell fractionation was performed as follows: cell lysates $(60-100 \mu \mathrm{g})$ were deglycosylated and VEGFR2 was detected by Western blotting with rabbit anti-VEGFR2 antibody (Santa Cruz Biotechnology). Affinity-purified secondary antibodies conjugated with horseradish peroxidase (Jackson ImmunoResearch Laboratories, West Grove, PA, USA) were used and immunoreactive proteins were visualized by the SuperSignal West Pico chemiluminescent substrate (Thermo Scientific, Rockford, IL, USA) and exposed to X-ray film.

ELISA. Supernatants of 24-h cell cultures were collected and centrifuged to eliminate cellular debris. VEGF expression was determined with a human VEGF ELISA kit (Quantikine; R\&D Systems) according to the manufacturer's instructions. 
Reverse transcriptase PCR and real-time PCR. Total RNA was prepared in Trizol (Invitrogen) according to manufacturer's instructions. RT-PCR was performed using the SuperScript III Platinum one step RT-PCR kit (Invitrogen). The primers used in this study were as follows: VEGFR1, sense $5^{\prime}$-CCT CACTGCCACTCTAATTGTC-3', antisense 5'-ACAGTTTCAGGTCCTCTCCTT-3'; VEGFR2, sense $5^{\prime}$-CTCATGTCTGAACTCAAGATCC- $3^{\prime}$, antisense $5^{\prime}$-CCAGAAT CCTCTTCCATGCTCA- $3^{\prime}$; and GAPDH, sense $5^{\prime}$-GACCCCTTCTTCATTGA CCTCAACT- $3^{\prime}$, antisense $5^{\prime}$-CACCACCTTCTTCTTGATGTCATC- $3^{\prime}$. PCR products were submitted to electrophoresis in agarose gels. The following primers for real-time PCR were obtained from TaqMan Gene Expression Assays (AB Applied Biosystems, Foster, CA, USA): VEGFR1 Hs01052937_ml, VEGFR2 Hs00176676 ml, and GAPDH Hs99999905 ml. cDNA products were diluted 10 times and $1 \mu$ l was used for real-time PCR using the Tap Man Universal PCR Master Mix (AB Applied Biosystems). The reactions were performed using 96-well plates in triplicate using the AB17700 Sequence Detection System (AB Applied Biosystems). The data were normalized by the data of GAPDH.

UV and anisomycin treatment. For UV treatment, HDMECs were preincubated with $0-10 \mu \mathrm{M} \mathrm{SP600125} \mathrm{(AG} \mathrm{Scientific)} \mathrm{for} 1 \mathrm{~h}$ and treated with UV $\left(254 \mathrm{nM}, 150-200 \mu \mathrm{W} / \mathrm{cm}^{2}\right)$ for $1 \mathrm{~min}$. Alternatively, cells were starved overnight and treated with $0-2.5 \mu \mathrm{g} / \mathrm{ml}$ anisomycin (Sigma) for the indicated time points (after $1 \mathrm{~h}$ pre-incubation with $0-10 \mu \mathrm{M}$ SP600125). At the end of the experimental period, cells were collected and Western blotting or RT-PCR was performed.

Flow cytometry. HDMECs stably transduced with shRNA-C, shRNAVEGFR1, or shRNA-VEGFR2 were cultured for $48 \mathrm{~h}$. Cells were counted, fixed in $70 \%$ ethanol for $1 \mathrm{~h}$ at $4{ }^{\circ} \mathrm{C}$, and resuspended in propidium iodide solution containing $0.1 \%$ sodium citrate, $25 \mu \mathrm{g} / \mathrm{ml}$ propidium iodide (Sigma), $100 \mu \mathrm{g} / \mathrm{ml}$ RNase $A$, and $0.1 \%$ Triton $X-100$. Cells were analyzed for DNA content by flow cytometry (FACSCalibur; BD Biosciences, San Jose, CA, USA). The proportion of cells in sub- $G_{0} / G_{1}, G_{1}, S, G_{2} / M$ phase was determined using the Modfit cell-cycle analysis software (Verity Software, Topsham, ME, USA).

Caspase-3 activity assay. shRNA-transduced HDMECs were cultured with EGM2-MV (Lonza, Walkersville, MD, USA) for $48 \mathrm{~h}$. Cell extracts were prepared and caspase-3 activity assay was performed at $37^{\circ} \mathrm{C}$ using $10 \mu \mathrm{M}$ Ac-DEVD-AMC (Alexis, San Diego, CA, USA). The caspase-3 inhibitor Ac-DEVD-CHO (Alexis) was used at $20 \mu \mathrm{M}$ to determine the specificity of reactions, and purified recombinant human caspase-3 (Alexis) was used as positive control. Caspase-3 activity was detected using a luminescence microplate reader (GENios, Tecan, Grödig, Austria) using $360 \mathrm{~nm}$ excitation and $465 \mathrm{~nm}$ emission wavelength.

Tumor-cell CM. UM-SCC-1 or OSCC3 were cultured for $24 \mathrm{~h}$ in serum-free medium (EBM2; Cambrex) and the supernatants were collected as CM. HDMECs were starved overnight and treated with UM-SCC-1 or OSCC3 CM in the presence of $0-50 \mu \mathrm{g} / \mathrm{ml}$ bevacizumab (Avastin; Genentech) or vehicle for $24 \mathrm{~h}$. VEGFR1, VEGFR2, and Bcl-2 expression was detected by Western blotting as described above.

Statistical analysis. Statistical analysis was performed by one-way ANOVA followed by post hoc tests for multiple group comparison using the SigmaStat 2.0 statistical software (SPSS, Chicago, IL, USA). The level of significance was determined at $P<0.05$.

Acknowledgements. We thank Dr Zhihong Dong for assistance with the SCID Mouse Model of Human Tumor Angiogenesis, and Dr Seungwon Kim for critically reading the paper and providing invaluable suggestions. This work was supported by grant R01-CA112390 from the NIH/NCl (LME); grant R01-DE12322 from the NIH/NIDCR (MWL); grant P50-CA97248 (University of Michigan Head and Neck SPORE) from the NIH/NCI (JEN); and grants R01-DE14601, R01-DE15948, R01-DE16586, and R21-DE19279 from the NIH/NIDCR (JEN).

1. Leung DW, Cachianes G, Kuang WJ, Goeddel DV, Ferrara N. Vascular endothelial growth factor is a secreted angiogenic mitogen. Science 1989; 246: 1306-1309.

2. Carmeliet P. VEGF as a key mediator of angiogenesis in cancer. Oncology 2005; 69 (Suppl. 3): 4-10.

3. Ellis LM, Hicklin DJ. VEGF-targeted therapy: mechanisms of antitumour activity. Nat Rev Cancer 2008; 8: 579-591.
4. Carmeliet P, Ferreira V, Breier G, Pollefeyt S, Kieckens L, Gertsenstein M et al. Abnormal blood vessel development and lethality in embryos lacking a single VEGF allele. Nature 1996; 380: 435-439.

5. Ferrara N, Carver-Moore K, Chen H, Dowd M, Lu L, O'Shea KS et al. Heterozygous embryonic lethality induced by targeted inactivation of the VEGF gene. Nature 1996; 380: 439-442.

6. Lee S, Chen TT, Barber CL, Jordan MC, Murdock J, Desai S et al. Autocrine VEGF signaling is required for vascular homeostasis. Cell 2007; 130: 691-703.

7. Kerbel RS. Tumor angiogenesis. N Engl J Med 2008; 358: 2039-2049.

8. Hurwitz H, Fehrenbacher L, Hainsworth JD, Heim W, Berlin J, Holmgren E et al. Bevacizumab in combination with fluorouracil and leucovorin: an active regimen for firstline metastatic colorectal cancer. J Clin Oncol 2005; 23: 3502-3508.

9. Kerbel RS, Yu J, Tran J, Man S, Viloria-Petit A, Klement G et al. Possible mechanisms of acquired resistance to antiangiogenic drugs: implications for the use of combination therapy approaches. Cancer Metastasis Rev 2001; 20: 79-86.

10. Miller KD, Sweeney CJ, Sledge GW. Can tumor angiogenesis be inhibited without resistance? EXS 2005; 94: 95-112.

11. Casanovas O, Hicklin DJ, Bergers G, Hanahan D. Drug resistance by evasion of antiangiogenic targeting of VEGF signaling in late-stage pancreatic islet tumors. Cancer Cell 2005; 4: 299-309.

12. Shibuya M, Yamaguchi S, Yamane A, Ikeda T, Tojo A, Matsushime $\mathrm{H}$ et al. Nucleotide sequence and expression of a novel human receptor-type tyrosine kinase gene (flt) closely related to the fms family. Oncogene 1990; 5: 519-524.

13. Matthews W, Jordan CT, Gavin M, Jenkins NA, Copeland NG, Lemischka IR. A receptor tyrosine kinase cDNA isolated from a population of enriched primitive hematopoietic cells and exhibiting close genetic linkage to c-kit. Proc Natl Acad Sci USA 1991; 88: 9026-9030.

14. Olsson AK, Dimberg A, Kreuger J, Claesson-Welsh L. VEGF receptor signaling - in control of vascular function. Nat Rev Mol Cell Biol 2006; 7: 359-371.

15. Waltenberger J, Claesson WL, Siegbahn A, Shibuya M, Heldin CH. Different signal transduction properties of KDR and Flt1, two receptors for vascular endothelial growth factor. J Biol Chem 1994; 269: 26988-26995.

16. Takahashi $H$, Shibuya $M$. The vascular endothelial growth factor (VEGF)/VEGF receptor system and its role under physiological and pathological conditions. Clin Sci 2005; 109 : 227-241.

17. Gille H, Kowalski J, Li B, LeCouter J, Moffat B, Zioncheck TF et al. Analysis of biological effects and signaling properties of FIt-1 (VEGFR-1) and KDR (VEGFR-2). A reassessment using novel receptor-specific vascular endothelial growth factor mutants. J Biol Chem 2001; 276: 3222-3230.

18. Huang F, Kirkpatrick D, Jiang X, Gygi S, Sorkin A. Differential regulation of EGF receptor internalization and degradation by multi-ubiquitination within the kinase domain. Mol Cell 2006; 21: 737-748.

19. Duval M, Bédard GS, Delisle C, Gratton JP. Vascular endothelial growth factordependent downregulation of Flk-1/KDR involves Cbl-mediated ubiquitination: consequences on nitric oxide production from endothelial cells. J Biol Chem 2003; 278: 20091-20097.

20. Ewan LC, Jopling HM, Jia H, Mittar S, Bagherzadeh A, Howell GJ et al. Intrinsic tyrosine kinase activity is required for vascular endothelial growth factor receptor 2 ubiquitination, sorting, and degradation in endothelial cells. Traffic 2006; 7: 1270-1280.

21. Dougher M, Terman BI. Autophosphorylation of KDR in the kinase internalization. Oncogene 1999; 18: 1619-1627.

22. Radhakrishnan R, Solomon M, Satyamoorthy K, Martin LE, Lingen MW. Tissue microarray - a high-throughput molecular analysis in head and neck cancer. J Oral Pathol Med 2008; 37: 166-176.

23. Fuchs SY, Xie B, Adler V, Fried VA, Davis RJ, Ronai Z. c-Jun NH2-terminal kinases target the ubiquitination of their associated transcription factors. J Biol Chem 1997; 272: 32163-32168.

24. Hibi M, Lin A, Smeal T, Minden A, Karin M. Identification of an oncoprotein- and UVresponsive protein kinase that binds and potentiates the c-jun activation domain. Genes Dev 1993; 7: 2135-2148.

25. Nör JE, Christensen J, Mooney DJ, Polverini PJ. Vascular endothelial growth factormediated angiogenesis is associated with $\mathrm{Bcl}-2$ upregulation and enhanced endothelial cell survival. Am J Pathol 1999; 154: 375-384.

26. Yu C, Minemoto Y, Zhang J, Liu J, Tang F, Bui TN et al. JNK suppresses apoptosis via phosphorylation of the proapoptotic Bcl-2 family protein BAD. Mol Cell 2004; 13 : 329-340.

27. Kim KW, Mutter RW, Cao C, Albert JM, Shinohara ET, Sekhar KR et al. Inhibition of signal transducer and activator of transcription 3 activity results in downregulation of survivin following irradiation. Mol Cancer Ther 2006; 5: 2659-2665.

28. Kitamura T, Asai N, Enomoto A, Maeda K, Kato T, Ishida M et al. Regulation of VEGF-mediated angiogenesis by the Akt/PKB substrate girdin. Nat Cell Biol 2008; 10: 329-337.

29. Mavria G, Vercoulen Y, Yeo M, Paterson H, Karasarides M, Marais R et al. ERK-MAPK signaling opposes Rho-kinase to promote endothelial cell survival and sprouting during angiogenesis. Cancer Cell 2006; 9: 33-44.

30. Hilfiker-Kleiner D, Hilfiker A, Fuchs M, Kaminski K, Schaefer A, Schieffer B et al. Signal transducer and activator of transcription 3 is required for myocardial capillary growth, 
control of interstitial matrix deposition, and heart protection from ischemic injury. Circ Res 2004; 95: 187-195.

31. Nishimura K, Li W, Hoshino Y, Kadohama T, Asada H, Ohgi S et al. Role of AKT in cyclic strain-induced endothelial cell proliferation and survival. Am J Physiol Cell Physiol 2006; 290: C812-C821.

32. Nör JE, Peters MC, Christensen JB, Sutorik MM, Linn S, Khan MK et al. Engineering and characterization of functional human microvessels in immunodeficient mice. Lab Invest 2001; 81: 453-463.

33. Kaneko T, Zhang Z, Mantellini MG, Karl E, Zeitlin B, Verhaegen M et al. Bcl-2 orchestrates a crosstalk between endothelial cells and tumor cells that promotes tumor growth. Cancer Res 2007; 67: 9685-9693.

34. Du R, Lu KV, Petritsch C, Liu P, Ganss R, Passegue E et al. HIF1-alpha induces the recruitment of bone marrow-derived vascular modulatory cells to regulate tumor angiogenesis and invasion. Cancer Cell 2008; 13: 206-220.
35. Karl E, Zhang Z, Dong Z, Neiva KG, Soengas MS, Koch AE et al. Unidirectional crosstalk between $\mathrm{Bcl}-\mathrm{X}_{\mathrm{L}}$ and $\mathrm{Bcl}-2$ enhances the angiogenic phenotype of endothelial cells. Cell Death Differ 2007; 14: 1657-1666.

36. Mittar S, Ulyatt C, Howell GJ, Bruns AF, Zachary I, Walker JH et al. VEGFR1 receptor tyrosine kinase localization to the Golgi apparatus is calcium-dependent. Exp Cell Res 2009; 315: 877-889.

37. Gerber HP, Dixit V, Ferrara N. Vascular endothelial growth factor induces expression of the antiapoptotic proteins Bcl-2 and A1 in vascular endothelial cells. J Biol Chem 1998; 273: 13313-13316.

38. Ferrara N, Gerber HP, LeCouter J. The biology of VEGF and its receptors. Nat Med 2003; 9: 669-676.

39. Shibuya M, Claesson WL. Signal transduction by VEGF receptors in regulation angiogenesis and lymphangiogenesis. Exp Cell Res 2006; 312: 549-560.

Supplementary Information accompanies the paper on Cell Death and Differentiation website (http://www.nature.com/cdd) 